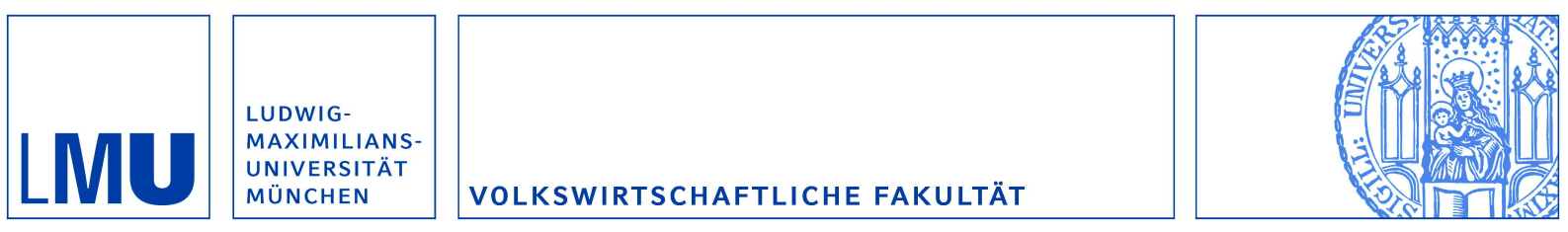

Sailer, Katharina:

Searching the eBay Marketplace

Munich Discussion Paper No. 2006-32

Department of Economics

University of Munich

Volkswirtschaftliche Fakultät

Ludwig-Maximilians-Universitäł München

Online at https://doi.org/10.5282/ubm/epub. 1234 


\title{
Searching the eBay Marketplace
}

\author{
Katharina Sailer*
}

This Version: October 2006

\begin{abstract}
This paper proposes a framework for demand estimation with data on bids, bidders' identities, and auction covariates from a sequence of eBay auctions. First the aspect of bidding in a marketplace environment is developed. Form the simple dynamic auction model with IPV and private bidding costs it follows that if participation is optimal the bidder searches with a "reservation bid" for low-price auctions. Extending results from the empirical auction literature and employing a similar two-stage procedure as has recently been used when estimating dynamic games it is shown that bidding costs are non-parametrically identified. The procedure is tried on a new data set. The median cost is estimated at less than $2 \%$ of transaction prices.
\end{abstract}

\section{Introduction}

The internet greatly reduced the transaction costs of selling objects via auctions and of participating in auctions. Entrepreneurs soon exploited this fact and developed platforms that offered standardized selling mechanisms on the basis of auctions which can be used by any interested

\footnotetext{
${ }^{*}$ Katharina Sailer, Munich Graduate School in Economics and Center for Information and Network Economics, University of Munich, Akademiestr. 1/I, 80799 Muenchen, Germany. E-mail: ksailer@stat.uni-muenchen.de. I am grateful to Sven Rady, Joachim Winter, and Stefan Mittnik for their advice and encouragement. This work also greatly benefited from comments by Patrick Bajari, Emmanuel Guerre, Martin Pesendorfer, Matthew Shum, and participants at the Kiel-Munich workshops, EARIE 2004, the 2004 EC2 conference, the Third bi-annual Conference on the Economics of the Software and Internet Industries, the 5th ZEW Conference on the Economics of ICT, the ESWC 2005 and the conference on the Econometrics of Auctions. I would like to thank the Volkswagen Stiftung, the Nixdorf Stiftung, and the German Science Foundation for the generous financial support which made this research possible.
} 
individual at low costs. The story of eBay is probably the most stunning one: Every day sellers now offer millions of items over individual eBay auctions. The auction house claims to be the most popular shopping address for online buyers. What once started off as an e-garage sale by now has become a fully developed marketplace for private and professional resale of new and used goods.

eBay's success story did not go unnoticed. eBay's reputation mechanism (e.g. Lucking-Reiley et al. (2000) and Houser and Wooders (forthcoming)) as well as aspects of its specific auction rules (e.g. Roth and Ockenfels (2002)) have received considerable attention in the scholarly literature. The rich and readily available data further has been used to infer bidders' valuations (e.g. Bajari and Hortacsu (2003) and Song (2004)). In all of this work the choice set of a bidder comprise a single eBay auction. Whenever a bidder comes to eBay, she though faces not one but a multitude of auctions, closing one after the other, of which many offer similar products. By employing a single-unit static auction framework the literature thus ignores a primary idiosyncracies of this type of market. Further, by focusing on very specific products within the group of collectibles, ${ }^{1}$ authors have lost sight of eBay's most important segment, that for standardized new products such as consumer electronics, computers, domestic appliances, DVDs, etc.

This paper argues that ignoring alternative auctions in the bidder's choice set leads to wrong conclusions about her behavior and, hence, delivers incorrect estimates of bidders' valuations. This is demonstrated with a simple dynamic bidding model whose assumptions provide a good description for auctions within eBay's off-the-shelf segment. The model emphasizes that, when confronted with an infinite sequence of stochastically equivalent auctions, bidders optimally try in several ones: At the beginning of each new auction a bidder chooses on the basis of her valuation for the product on offer and her bidding costs whether to participate in this specific auction; when participating, it is then optimal not to bid her valuation but her valuation less her continuation value. The additive continuation value causes that non-parametric identification of valuations is, without further assumptions, only possible up to location. The panel structure of the data though allows to fully identify another interesting bidder characteristic, namely her costs. Using data from auctions for a PDA (personal digital assistant or palm pilot) from eBay.de

\footnotetext{
${ }^{1}$ See e.g. Lucking-Reiley, Bryan, Prasad and Reeves (forthcoming) and Bajari and Hortacsu (2003) for coins, Song (2004) for university yearbooks, and Jin and Kato (forthcoming) for baseball cards.
} 
it is shown that the model delivers realistic estimates for these parameters.

The model assumes that when coming to eBay, a bidder faces an infinite sequence of Vickrey auction which offer comparable products. Her problem is to acquire one product for a reasonably cheap price. In principle she can try as often as she wishes. However, bidding is costly. When thinking about optimal strategies, the bidder first weights the cost of participation against its expected return. The latter depends not only on her own bid but also on competitors' behavior. Assume, bidders believe that competitors' bids always represent a random draw from the same distribution. The bidder then basically faces an optimal stopping problem. Consequently, if participation is optimal, she searches with a "reservation bid" for low-price auctions. The reservation bid consists of shading her valuation by her continuation value. ${ }^{2}$

A key characteristic of the model is that bidders find it costly to bid. These costs reflect, e.g., the time spent in front of the computer when placing a bid and connection charges. ${ }^{3}$ In this model costs are allowed to differ: Some bidders mind the time lost while bidding more than others; similarly, while some bidders have access to a fast Internet connection or are allowed to use their computer at work, others rely on a slow modem and bear the connection charges themselves. Different costs lead to different continuation values and hence different bidding strategies: The higher a bidders costs, the more aggressive she bids to prevent having to bid often. Consequently, observed bids and transaction prices differ. This reflects insights from the search literature: Price dispersion is caused by search frictions.

The model further relies on the assumption that a bidder does not update her beliefs about a specific competitor after participating in an auction. This provides a good approximation to eBay's off-the-shelf segment. If there is a lot of entry and exit and stochastic components to valuations, ${ }^{4}$ updating the beliefs about a specific competitor provides little payoff since the bidder is neither sure that this competitor will also bid in the next auction nor what his valuation will be. The assumption also implies, an individual bidder can influence neither the number nor the future distribution of competitor's characteristics by his current bid or participation

\footnotetext{
${ }^{2}$ This is a well known result from the sequential auction literature. Standard sequential auction models, however, do not provide a good approximation to the eBay market since they assume a fix pool of products for which a much larger number of predetermined bidders compete until none is left.

${ }^{3}$ See also Bajari and Hortacsu (2003).

${ }^{4}$ For stochastic valuations in sequential auctions see e.g. Engelbrecht Wiggans (1994).
} 
decision. It thus reflects the marketplace characteristic of eBay, which means, competition among a multitude of anonymous strangers.

Estimation of the parameters of interest, namely the distribution of valuations and the individual bidding costs, is complicated by unobserved winning bids, endogenous selection, and correlation across bids of the same bidder. Further, there is no closed from solution for the value function as a function of the unobserved costs. Full information Maximum Likelihood inference is thus computationally intensive and would have to rely on several parametric assumptions. I suggest a stepwise procedure instead which allows me to show, both the distribution of valuations (up to location) and the costs are non-parametrically identified from the data.

First, valuations are inferred by exploiting information on the ordering of the observed and unobserved bids as is done in the empirical auction literature (for overviews see Laffont and Vuong (1996), Hendricks and Porter (forthcoming), or Athey and Haile (2002)). For this purpose an identification result by Song (2004) is extended to the case of asymmetric bidders: Information on the second and third highest bid and on the identities of the winner and the second highest bidder identifies the individual parent bid distributions. From the bid distributions the distribution of valuations is identified up to location. Next, the parent bid distributions are used to provide estimates of the unobserved winning bids, the highest bid of the competitors, and bidders' winning odds. With this information it is finally possible to compute a bidder's costs from an optimality condition of the model.

The approach to first estimate the winning odds and then use these estimates to infer model parameters, here the costs, from observed optimal strategies is similar in spirit to Guerre, Perrigne and Vuong (2000). The stepwise procedure resembles the approach used in the literature on estimating dynamic games (see Bajari, Benkard and Levin (forthcoming) and Pakes, Ostrovsky and Berry (forthcoming)): Computation of the value function can be circumvented by first estimating those structural parameters which determine per period optimal policies and then estimating the parameters which affect behavior only via dynamic considerations from equilibrium conditions.

The procedure is tried on a new data set eBay.de auctions for a Compaq PDA with a mean transaction price of $469 €$. First, the distribution of bidders' valuations is recovered. Secondly, individual specific bidding costs are computed. This additional information derives from the bidders' participation decision and from the fact that at eBay bidders are observed with their 
identities over a sequence of auctions. The resulting distribution of costs is highly skewed with a median of less than $2 \%$ of the average transaction price.

While the estimation procedures differ, it is interesting to compare the results to those obtained in the search literature. Estimating search models has a long history in the labor market literature (e.g. van den Berg and Ridder (1998)). Recent contributions in IO are Sorensen (2001), Hong and Shum (2006), and Hortacsu and Syverson (2004). The search costs which are needed to justify the observed price dispersion are often very high. The advantage of the data from eBay is that the "reserve bid" is observed in every auction, even when a bidder is not winning, and that very detailed information on the covariates is available. This allows to distinguish price dispersion caused by search frictions from that induced by product differentiation. The costs which are estimated here are lower than in both Sorensen (2001) and Hong and Shum (2006).

The next section introduces the model. The data is described in section 3. Section 4 discusses identification while section 5 goes into the details of the estimation procedure. The results are provided in Section 6. Section 7 concludes.

\section{Model}

Besides being a rich source for observing strategic interaction among individuals, auction data became the focus of empirical work since, as opposed to many other situations where people interact, the rules of the game are explicitly stated and common knowledge to all participants at the outset of the game. Also, many of the auctions for which data is available, e.g. procurement auctions, have been designed by economists and therefore come close to what is taught in theory. Models for a structural empirical analysis are therefore readily available. This does not hold true for eBay. Its setting does not fit any of the textbook examples. Further, details in the rules are left to the discretion of the competing parties.

The paper thus starts with a stylized bidding model for eBay. After a brief description of the eBay environment, the main assumptions of the model are stated. Next I derive bidders' optimal strategies in a simplified version of the setting. While being too stylized for an empirical analysis it helps to understand the basic features of the model. In subsection 2.3, optimal strategies under the general setup are analyzed. To be able to model the trade-off between bidding today and 
waiting for tomorrow, I have to abstract from other aspects in the bidder's decision problem. This section therefore concludes with a critical discussion of the model's assumptions and its limitations.

\section{1 eBays Rules and Model Setup}

When searching at eBay's homepage for a certain product, a potential bidder gets back an overview list with auctions which all offer variants of the product. When clicking into the items of the list the bidder is directed to individual auction pages where she finds detailed information. The choice set of the bidder comprises the auctions in the initial list and all ensuing ones. There is no restriction as to how many auctions a bidder can participate in, neither simultaneously nor over time. In each auction the bidding rules allow a bidder to either bid incrementally as in an English auction or to submit her maximum willingness to pay to a proxy bidding software that will then bid for her. Sellers can specify the minimum bid ${ }^{5}$ and the length of an auction. From the latter it follows that there is a "hard close", that is, an auction ends when time is up and not when bidding activity ceases. ${ }^{6}$ The rules do not specify when a bidder can enter an auction: Bidder's are free to abstain from bidding for a while or to only enter in the last seconds of the auction. Furthermore, the pool of active bidders permanently changes since some bidders retire from bidding while new ones get interested in the product and join the pool. Thus, a bidder never knows for sure how many people are currently competing for the product nor whether the observed bid is the final bid of a competitor.

The following six assumptions are the building blocks for a model which aims to capture essential features of this environment.

Assumption 1. Vickrey Auction. The bidding rules in each auction can be approximated by a Vickrey auction.

By assuming a second price sealed bid auction, I claim, that all that matters in an eBay auction are the last minutes when bidders cannot observe their competitors' actions anymore.

\footnotetext{
${ }^{5}$ At eBay.de there exists no secret reserve price.

${ }^{6}$ If no bid is yet placed, auctions can also be stopped by "buy-it-now" (byn) given the seller made the option available. Since I do not have enough information on this option in the data, I will ignore it in the following. The model could though explain why bidders take this option: If buying by byn is less costly since less time consuming than bidding, bidders would exercise the option if the byn price it not too high.
} 
Most data sets on eBay, including my own, show a pronounced increase in bidding activity towards the very end of an auction; actual bidder's thus seem to find it in their best interest to bid late. The literature on eBay provides several reasons why a bidder might be reluctant to reveal private information during the course of an auction (see e.g. Roth and Ockenfels (2002), Bajari and Hortacsu (2003), Wang (2003)). In contrast, there is, to my knowledge, no theoretical evidence how early bidding could benefit a bidder.

Assumption 2. Discrete Time Infinite Horizon. In each period $t=1, . ., \infty$ a new Vickrey auction for the product is on offer.

Since by Ass. 1 all that matters is the end, auctions can be sorted into a sequence. Sequential second price auctions have been studied before (e.g. Weber (2000)). This literature, however, starts from a finite pool of products for which a much larger number of bidders compete until none is left. At eBay new sellers can enter the marketplace whenever they want. As long as the number of products is not limited exogenously - which is unlikely in the case of off-the-shelf products - it is thus more appropriate to approximate the supply side by an infinite number of auctions. For simplicity time will be discrete and in each period exactly one auction is open.

Assumption 3. IID Shocks. Supply side details $\mathbf{s}_{t}=\left(\mathbf{x}_{t}, \mathbf{a}_{t}\right)$ are drawn at the beginning of each period independently from a distribution $F_{\mathbf{s}}$ with compact support $\mathbf{S}$.

At eBay products are rarely exactly the same: Some are new others used, some come with additional extras or have little defects, etc. Instead of homogenous products I thus assume stochastically equivalent ones. Also details in the auction rules change. Both, product characteristic, $\mathbf{x}_{t}$ and auction details, $\mathbf{a}_{t}$, here a minimum bid (reserve price, $r_{t}$ ) and the duration of an auction, follow an iid stochastic process. Details of future auctions are only realized after the preceding auction ended.

Ass. 1 - 3 summarize the supply side. It can already be seen that a bidder who participates in the game faces an intertemporal optimization problem. In solving the model I restrict attention to Markov perfect equilibria in pure and symmetric strategies. Given such strategies exist, they will, besides the supply side state variables, depend on bidders' characteristics:

Assumption 4. IPV. Each potential bidder $i$ is interested in one product only. As long as she is still active, she draws her valuation, $v_{i t}$, after the realization of $\mathbf{s}$ from a continuous density $f_{v}\left(\cdot \mid \mathbf{x}_{t}\right)$ defined on $\left[\underline{v}\left(\mathbf{x}_{t}\right), \bar{v}\left(\mathbf{x}_{t}\right)\right]$. It remains private information. 
The focus of this paper is on eBay's market segment for off-the-shelf products that are frequently sold outside eBay. They are presumably mainly acquired for personal usage. The PV assumption therefore seems more applicable and is taken as a good approximation to the true model. ${ }^{7}$ The valuation depends on product characteristics and bidder i's preferences. Conditional on product characteristics, valuations are independent across individuals and over time. The assumption that the bidder is not interested in more than one product reflects the data.

Assumption 5. Private Bidding Costs. Bidder $i$ incurs a bidding cost $c_{i}$. It is drawn before entering the market for the first time from a common and continuous density $f_{c}(\cdot)$ defined on $[\underline{c}, \bar{c}]$. It remains constant over time and private information.

While there is no cost in money terms for a bidder to participate in an eBay auction nor for buying the product, ${ }^{8}$ bidders have to spent time sitting in front of the computer and pay connection charges. Bidders presumably differ in the value they attach to their time, in their connection speeds and connection costs. Therefore, these costs differ across bidders.

The personal characteristics of bidder $\mathrm{i}$ in auction $\mathrm{t}$ are summarized by the vector $\nu_{i t}=$ $\left(v_{i t}, c_{i}\right)$ with density $f_{\nu}\left(\nu_{i t} \mid \mathbf{x}_{t}\right)=f_{v}\left(v_{i t} \mid \mathbf{x}_{t}\right) f_{c}\left(c_{i}\right)$.

From here if follows that a bidder has two strategic variables. Given positive bidding costs, she has to decide whether to participate in auction $\mathrm{t}\left(\delta_{i t}=1\right)$ or not $\left(\delta_{i t}=0\right)$. Let $D_{i t}$ denote the set of $v_{i t}$ for which participation of bidder i with $\operatorname{cost} c_{i}$ is profitable in t:

$$
D_{i t}=D\left(c_{i}, \mathbf{s}_{t}\right)=\left\{v_{i t}: \delta_{i t}^{*}=\delta\left(v_{i t}, c_{i}, \mathbf{s}_{t}\right)=1\right\}
$$

When participation is optimal, the bidder places her optimal bid:

$$
b_{i t}^{*}=b\left(\nu_{i t}, \mathbf{s}_{t}\right)=b_{i t}\left(\nu_{i t}, \mathbf{s}_{t}\right){ }^{9}
$$

Note that the strategies do not include any state variables which describe competitors. This is correct under the following assumption which completes the setup:

\footnotetext{
${ }^{7}$ See Bajari and Hortacsu (2003) for common values and the winners curse in the market for coins at eBay.

${ }^{8}$ eBay does not charge bidders any fee. Instead, it charges a fixed listing fee to sellers which varies with the auction details a seller chooses and a variable sales commission. eBay forbids sellers to role this fee over to bidders.

${ }^{9} \mathrm{I}$ assume, a bidder can choose any bid on the real line, that is, I ignore the minimum increment of $1 €$ that eBay's rules require since it is very small compared to the average transaction price. I further assume, bidding strategies are differentiable and monotone in $v_{i t}$ and $c_{i}$.
} 
Assumption 6. Stationary Distribution of Competitors' Characteristics. In each auction $t$ the vector of competitors' characteristics $\nu_{-i, t}$ is drawn from $f_{\nu_{-i} \mid \mathbf{x}}=f_{\nu}(\nu \mid \mathbf{x})^{m-1}$.

Assumption 6 comprises various aspects. First of all, the number of potential bidders stays constant over time: $m_{t}=m$. Secondly, entry and exit does not influence the distribution of competitors characteristics. Finally, bidders believe that the draw of their potential competitors' valuations conditional on product specific covariates invariantly comes from the same distribution. This excludes learning about the characteristics of any specific competitor from past interaction. Given that bidders' identities are available at eBay a bidder could in principle follow her competitors' behavior over time. Here the view is taken that due to noise, which is introduced by entry and exit and stochastic components in valuations, the scope of learning is so limited that none of the bidders finds it worth while to do so.

Instead of assuming stationarity exogenously, one could think of entry and exit processes and distributions which would achieve stationarity endogenously. Since this would lead to considerable complications in the modelling without adding explanation a 'reduced form' approach is taken here.

To summarize, the timing of the events and the information structure is as follows: First, new entrants receive their cost draw from the common density $f_{c}$. Then, the auction specifics $\mathbf{s}$ are realized and observed by everybody. The potential bidders draw their private valuation for the product on offer from the common density $f_{v \mid x}$ and compute their optimal bid. Each bidder next considers whether participation is profitable for her or not. Given participation, the bidder places her bid. In case she wins, she leaves the auction market and a new bidder enters. Otherwise, she continues and starts evaluating the auction that closes next.

\subsection{The Bidders' Problem in a Static Environment}

It remains to be shown that the optimal strategies stated in the last paragraph do exist as the outcome of a bidder's optimization problem and see whether they can be characterized more closely. Let's first look at a simple example where a bidder's valuation is independently drawn from a common density $f_{v}$ and remains constant over time: $v_{i t}=v_{i}$. This characterizes a situation with fully homogenous products. Further, there is no variation in the auction details. While being highly stylized and therefore not useful for the purpose of empirical analysis, this setting best illustrates the search aspect in the bidder's behavior. 
The bidder's problem is to choose a strategy which maximizes her expected intertemporal utility given the potential competitors play optimally. It can be represented by the following Bellman equation:

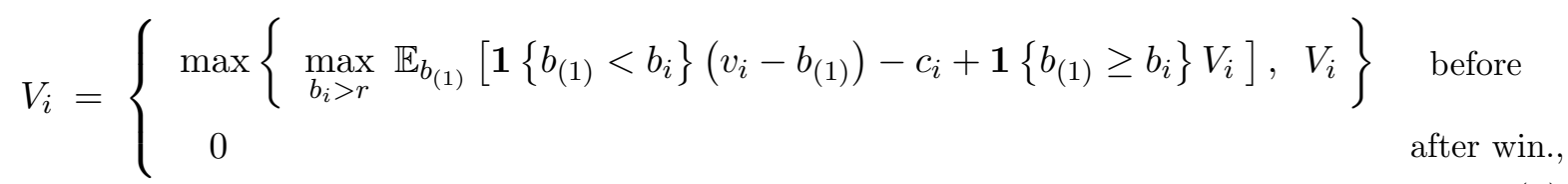

where $\mathbf{1}\{\cdot\}$ denotes the indicator function and $b_{(1)}=\max _{j \neq i}\left\{b_{j}^{*} \mid \delta_{j}^{*}=1\right\} .{ }^{10} \mathrm{~A}$ bidder who decides to participate and wins, which is the case when her bid is higher than the highest of the competitors, gets her valuation and pays the price determined by the bid of the second highest bidder in the auction. She then enters the absorbing termination stage where period rewards are zero. If she looses, she gets the continuation value $V_{i}$. In any case she pays the bidding costs. If the bidder decides not to participate, she receives the option to participate again tomorrow, $V_{i}$. Since the option value depends on the bidder's cost, it is different for different bidders.

The bidder has two decision variables. The optimal bid is given by: ${ }^{11}$

$$
b_{i}^{*}=b\left(\nu_{i}\right)=v_{i}-V_{i}
$$

This bid is constant over time. Since the environment does not change, a bidder also decides only once whether to participate or not. If participation is optimal in the first round, it will be so in all following ones until the bidder wins and her valuation drops to zero. In this static environment, it is optimal for a bidder to enter when her option value is above zero: $\delta_{i}^{*}=1\left\{V_{i}>0\right\} .{ }^{12}$ Substituting the bid back into the Bellman equation for the case that participation is optimal and rearranging finally gives:

$$
c_{i}=\mathbb{E}_{b_{(1)}}\left[\mathbf{1}\left\{b_{(1)}<b_{i}^{*}\right\}\left(b_{i}^{*}-b_{(1)}\right)\right]
$$

An optimal bidding policy thus equates the cost of bidding with the expected gain from winning in a new trial.

\footnotetext{
${ }^{10}$ To be fully correct a law of motion for the single state variable $\chi_{i}$, with $\chi_{i}=1$ denoting an active bidder and $\chi_{i}=0$ a bidder who already won, has to be specified. This is given by: $\chi_{i}^{\prime}=\mathbf{1}\left\{b_{(1)} \geq b_{i}\right\} \chi_{i}$ with $\chi_{i 0}=1$. I avoid this formulation since it distracts from the main points.

${ }^{11}$ For the derivation see the proof of Prop. 1.

${ }^{12}$ It is assumed, if entry is profitable today, the bidder prefers to enter today instead of waiting for tomorrow.
} 
The bidder's decision rule here appears as myopic as that of the decision maker in an optimal stopping problem which is at the basis of search models, known for example from the labor market literature (see e.g. Albrecht and Axell (1984) and Burdett and Mortensen (1998)) or the IO literature where a seller faces uncertain demand (see the seminal work by Diamond (1971) and Rob (1985) for a model with heterogenous costs.). There the decision maker decides on a reservation value which serves as a cutoff value for accepting a price or a wage offer. This reservation value is found by equating the cost from one further search with the expected gain from this search. As long as the environment is constant, that is the state variables do not change over time, there is no added value in deciding sequentially. This holds true for both the auction and the standard search setting. In both cases the state variable only changes once, namely when the decision maker succeeds. The distribution of other bidders' bids and the wage or price offer curve stay constant.

\subsection{The General Problem}

The model described so far assumed an infinite sequence of identical products. At eBay there are hardly any two products that are exactly the same. It is therefore necessary to allow for valuations that take account of product heterogeneity. Additionally, details in the auction rules can change. I therefore turn to the case of exogenous variation in the bidding environment as described in subsection 2.1. The bidder's problem including a minimum bid now is:

$V_{i}\left(v_{i}, \mathbf{s}\right)= \begin{cases}\max \left\{\max _{b_{i}>r} \mathbb{E}_{b_{(1)}}\left[\mathbf{1}\left\{b_{(1)}<b_{i}\right\}\left(v_{i}-b_{(1)}\right)-c_{i}+\mathbf{1}\left\{b_{(1)} \geq b_{i}\right\} V_{i}^{e} \mid \mathbf{s}\right], V_{i}^{e}\right\} & \text { before } \\ 0 & \text { after win. },\end{cases}$

where $V_{i}^{e}$ denotes the expected future payoff when the bidder stays active defined by:

$$
V_{i}^{e}=\int_{\mathbf{S}} \int_{\underline{v}\left(\mathbf{x}^{\prime}\right)}^{\bar{v}\left(\mathbf{x}^{\prime}\right)} V_{i}\left(v^{\prime}, \mathbf{s}^{\prime}\right) d F_{v}\left(v^{\prime} \mid \mathbf{x}^{\prime}\right) d F_{\mathbf{s}}\left(\mathbf{s}^{\prime}\right) .
$$

The main difference to before is that the continuation value now includes an expectation over the unknown own future valuations for the products and the future realizations of the supply side details.

The following proposition establishes the bidder's optimal bidding strategy and the existence of a non-degenerate distribution of the maximum bid of the competitors, given these behave optimally as well. All details of the computation are provided in the appendix. 
Proposition 1. Under Assumptions 1-6, the following holds for a risk neutral bidder $i$ with cost $c_{i}$ who faces an infinite sequence of Vickrey auctions:

(a) Optimal Bidding Strategies. The bidder computes her optimal bid as:

$$
b_{i}^{*}=b\left(\nu_{i}\right)=v_{i}-V_{i}^{e}
$$

This bid is placed when $b_{i}^{*}>r$ and $\delta_{i t}^{*}=1$.

(b) Distribution of the Maximum. If all competitors behave optimally there exists a nondegenerate distribution of the maximum bid of the competitors.

Proof. See appendix.

Note that a bidder still shades her valuation by her option value. As before, the option value is individual specific because of the differing costs. As in any second price auction, the optimal bid does not respond to changes in current auction details such as the reserve price; different product characteristics, however, now make it optimal to adapt it over time.

If participation is optimal, then the following condition holds:

$$
c_{i} \leq \Pi\left(b_{i}^{*}, 1, \mathbf{s}\right)
$$

where the expected return from participating and winning is defined by:

$$
\Pi\left(b_{i}^{*}, 1, \mathbf{s}\right) \equiv E_{b_{(1)}}\left[\mathbf{1}\left\{b_{(1)}<b_{i}^{*}\right\}\left(b_{i}^{*}-b_{(1)}\right) \mid \delta_{i}^{*}=1, \mathbf{s}\right] .
$$

Condition 9 follows from the fact that a bidder participates in an auction when the expected return form participation with an optimal bid is higher than the return form waiting to the next auction. Given the possible changes in $v$ and $\mathbf{s}$, the bidder now might participate in some of the auctions where her valuation is high or auction details are favorable and stay out of others.

The following lemma shows, the analogy to the search setting is still given:

Lemma 1. Optimality condition. A bidder's optimal bidding policy given participation equates:

$$
c_{i}=\frac{\int_{\mathbf{S}} \int_{D\left(c_{i}, \mathbf{s}^{\prime}\right)} \Pi\left(b\left(v, c_{i}\right), 1, \mathbf{s}^{\prime}\right) d F_{v}\left(v \mid \mathbf{x}^{\prime}\right) d F_{\mathbf{s}}\left(\mathbf{s}^{\prime}\right)}{\int_{\mathbf{S}} \int_{D\left(c_{i}, \mathbf{s}^{\prime}\right)} d F_{v}\left(v \mid \mathbf{x}^{\prime}\right) d F_{\mathbf{s}}\left(\mathbf{s}^{\prime}\right)}
$$

which implicitly defines $V_{i}^{e}$.

Proof. Insert the optimal participation strategy $\left(v \in D\left(c_{i}, \mathbf{s}^{\prime}\right)\right)$ and the optimal bid into (7) using (6) and rearrange. 
The difference to before is that the future return now depends on the realizations of the shocks. The optimal bid is hence chosen such that the expected return, conditional on participation, is equivalent to the cost of participation.

Lemma 2 finally summarizes some results which will prove useful in the empirical part:

Lemma 2. Comparative Statics.

(a) Bidders with higher draws of $v$ are more likely to enter an auction. The set of $v$ for which bidder $i$ with costs $c_{i}$ and auction characteristics $\mathbf{s}_{t}$ will enter is given by $D_{i t}=$ $\left[g_{v}\left(c_{i}, \mathbf{s}_{t}\right), \bar{v}\left(\mathbf{x}_{t}\right)\right]$ if $g_{v}\left(c_{i}, \mathbf{s}_{t}\right) \in\left[\underline{v}\left(\mathbf{x}_{t}\right), \bar{v}\left(\mathbf{x}_{t}\right)\right]$.

(b) $V^{e}$ decreases in $c$, hence $b^{*}$ increases in $c$.

Proof. See appendix.

The last part of Lemma 2 shows, a bidder bids more aggressively the higher her costs. This reflects the fact that bidders with higher bidding costs have a lower continuation value and therefore shade their bids less. Current costs on the other hand are sunk. The first part states that only bidders with sufficiently high $v$ will enter an auction. While one might suspect, there is also a single cutoff value for the costs, that is, only bidders with low enough costs would enter an auction, this cannot be proven without further assumptions on the functional forms. The reason for this indeterminacy is that the costs influence the entry decision not only directly but also indirectly via the winning probability.

\subsection{Discussion}

The model leaves out complexity which cannot be reproduced in the econometric part. The following discussion shows why Ass. 1 - 6 are chosen, though they are overly restrictive for the theoretical model.

Vickrey assumption. Roth and Ockenfels (2002) show that "sniping", that is, bidding in the very last second, is a dominant strategy when a bidder faces other bidders who bid incrementally. The argument is, by bidding late, bidders avoid price wars. Bajari and Hortacsu (2003) look at a common value setting. Bidding early cannot be advantageous since it reveals valuable information on the bidder's signal. Wang (2003) shows that a common value component is introduced into the private value setting when there is a series of auctions featuring the same 
product: Since sequential auctions lead to bid shading and the amount of shading depends on expectations about future competitors' bids, different bidders' expectations contain a common component. Still, in reality, some bidders submit bids early on or even bid repeatedly within one auction. Song (2004) provides a very general setup for intra-auction dynamics where, within an IPV model, bidders might submit a bid smaller or equal to their valuation at all their monitoring opportunities but will submit their valuation at their last monitoring opportunity if they have not done so yet. While this model can explain different bidding patterns it cannot rationalize why a bidder would chose one over the other. Further, when bidding costs are introduced, many of the strategies would probably be suboptimal. While I think modelling intra-auction dynamics is interesting from a theoretical viewpoint and could add explanation to the data, postponing it to future research is justified by the rather small fraction of bidders who do so.

IID shocks. Ass. 3 has two implications: First, sellers do not choose $\mathbf{s}_{t}$ strategically. Including a strategic seller side, though interesting, is beyond the scope of this paper. Second, the $\mathbf{s}_{t}$ of the next auction realize after the entry and bidding strategy in the current auction is decided upon. This implies that a bidder considers the auctions in the overview list one after the other, first looking at the one that closes next. A bidder thus is not allowed to jump directly to auctions in the search list that attract her attention most nor can she act forward looking and have a number of auctions in her choice set when starting to bid in one of them. Zeithammer (n.d.) discusses how forward looking behavior with respect to future product characteristics can be included into a bidding model and presents reduced form estimation results that give evidence in favor of such a behavior. While in principle forward looking behavior could be included into the model via additional state variables, it would increase the computational burden in the empirical analysis in a non trivial way. ${ }^{13}$ Further, it is hard to judge for the econometrician which other auctions the bidder actually investigated more closely before placing her bid since there is no click data available. I therefore opt for ignoring this aspect of a bidders' search. Given the specific market segment I have in mind, where new auctions on similar products open every few hours, I though believe, this simplification does not present a major restriction.

IPV. At this point I do not allow for any difference in the valuations for product charac-

\footnotetext{
${ }^{13}$ Searching for all products that include the words "Compaq" and "3850" in the category "PDA's and Organizers" returns a list with usually more than 50 items. Including all details of these auctions would considerably augment the state space.
} 
teristics across agents nor for any private information on valuations that is carried over from period to period (see also Engelbrecht Wiggans (1994) and Jofre-Bonet and Pesendorfer (2003)). While both extensions seem interesting and are feasible from the point of view of the model (see e.g. subsection 2.2 ) they would cause non-trivial complications for identification and estimation since they add additional layers of correlation.

Bidding Costs. Buying a product at eBay certainly is a costly process for most bidders. It is though not evident that these costs only accrue while placing a bid. They rather accumulate during the whole process and involve i) one time costs of learning the eBay rules, ii) information costs, $c_{\text {info }}$, and iii) bidding costs. The decision to stick to the bidding costs is once again driven by identification. It is straightforward that any onetime cost of learning how to play eBay's rules is not identified without data on people who consider bidding at eBay but decide not to. Identifying $c_{\text {info }}$ separately would require click data or data from eBay about which auctions were observed. Also this is not available in my data set. Finally, from a technical perspective positive bidding costs cause a bidder not bid infinitely many times with a bid close to zero and thus serve the same purpose as a discount factor, $\beta$. Including both would be possible in the model, $\beta$ would though not be identified from the data. Given that the time between auctions is very short I believe, costs provide a better explanation. Including $c_{\text {info }}$ and $\beta$ in the bidders problem would alter the bidding strategy and the optimality condition as follows:

$$
\begin{aligned}
c_{i}+c_{\text {info }}+(1-\beta) V_{i}^{e} & =\frac{\int_{\mathbf{S}} \int_{D\left(c_{i}, \mathbf{s}^{\prime}\right)} \Pi\left(b\left(v, c_{i}\right), \mathbf{s}^{\prime}\right) d F_{v}\left(v \mid \mathbf{x}^{\prime}\right) d F_{\mathbf{s}}\left(\mathbf{s}^{\prime}\right)}{\int_{\mathbf{S}} \int_{D\left(c_{i}, \mathbf{s}^{\prime}\right)} d F_{v}\left(v \mid \mathbf{x}^{\prime}\right) d F_{\mathbf{s}}\left(\mathbf{s}^{\prime}\right)} \\
\text { with } b_{i}^{*} & =v-\beta V_{i}^{e}
\end{aligned}
$$

The latter cost estimates thus provide an upper bound to the true bidding costs. The estimates of valuations are not affected.

Supply of Auctions and Entry and Exit by Bidders. While the number of actual bidders in a specific auction is derived by individual rationality conditions, the number of potential bidders is assumed to stay constant. Also in each period exactly one auction is open. Letting the relation between supply and demand change over time would be an interesting extension and would fit the actual situation better. Exit is already stochastic in the model since some auctions do not receive bids and therefore after some of them no bidder leaves the market. Adding additional noise is possible. It could take the form of an exogenous exit probability which would mean that some bidders would leave the market without winning and zero payoff. Alternatively, 
bidders could start with an outside option which changes over time. This could e.g. induce a formerly active bidder to leave the market for good. Neither the exit probability nor the size of the outside option is though identified from the data. Allowing for stochastic entry or stochastic arrival of auctions is a non-trivial extension, since the different stochastic process would have to be brought in line to not run out of auctions or out of bidders.

No updating of beliefs. This assumption is from the model perspective the most critical one. Allowing for an endogenous distribution of competitors bids including entry and exit, that is modelling the full fledged dynamic game, is beyond the scope of this paper. While it would be interesting from a theoretical perspective I though believe, richer dynamic strategies have a negligible influence on the data in this segment. The following discussions provides some thoughts on what could happen.

There are several ways how a bidder could alter her strategies when confronted with a dynamic game: First, she could misrepresent her valuation in her bid. To see why, go back to the original sequential auction model by Weber (2000). There it is optimal to bid the valuation minus the continuation value. The first auction thus provides a complete ranking of competitors' valuations. If there are two auctions and bidding is costly, only the second highest bidder in the first auction will find it profitable to enter the second auction. All the others know, they have no chance of winning and are therefore reluctant to incur the bidding costs. The winner in the second auction then pays a price of zero. Since everybody foresees that, bidders will not find it optimal to follow the aforementioned strategies. ${ }^{14}$

Instead of changing the bidding strategy, bidders might also just decide to stay out of some of the auctions but to reveal truthfully when entering (strategic non-participation). If bidders know, they have no chance of winning since they experienced in past auctions that there are many high value bidders currently in the market they might want to stay out until they believe,

\footnotetext{
${ }^{14}$ von der Fehr (1994) shows, in a two-objects-many-bidders model there is room for predation. While the bids in the first auction still provide a complete ranking of bidders' valuations, bids are higher than in Weber (2000). Bidder's might even bid more than their valuation for obtaining the chance of being the only bidder in the highly profitable second auction. The optimality of this predatory strategy hinges on the assumption that there is a limited number of objects available, that is, not every bidder will receive one. The proof does not necessarily carry over to the case where an infinite number of objects are on offer. To see why, note that predation is costly since it includes the danger of winning the object for a price higher than one's valuation. Incurring these costs might not be optimal if bidders could obtain the object at a later instant when the high value bidders exited.
} 
the high value bidders left. ${ }^{15}$ As argued before, inferring which of her competitors will enter the next auction and with which valuation is, however, rather difficult for a bidder at eBay. While bidders in the data rarely interact twice with the same person there is no correlation between a bidder's rank in an auction which she looses and the number of auctions she passes before trying again.

\section{Data and Preliminary Evidence}

\subsection{The Data Set}

For the estimation information on eBay auctions for a frequently sold and well-delimited product with little substitution towards competing products is required. My data set comprises all auctions for a PDA (personal digital assistant), the Compaq Ipaq H3850, which closed during April to November 2002 on eBay.de. For the estimation I use a subsample of 840 auctions. $^{16}$ Table 1 reports summary statistics of these auctions. Every day around 5 auctions for this product closed. While the base product is always the same, smaller product characteristics differ: some are used, come with extras, have smaller defects or foreign operating systems. An asset of the data set is that it includes detailed information on all these characteristics: ${ }^{17} 37 \%$ of the auctions offered new products, $33 \%$ were bundled with extras, $3 \%$ had a defect such as scratches or missing standard accessory, and $4 \%$ came with a non-German operating system.

Winners paid on average $469 €$ for their Ipaq. Transaction prices are further characterized by a high standard deviation, partly due to differing product characteristics but also caused by a pronounced decrease in the average transaction price during the sample period (see Figure 1 (a)). This is most likely due to the high-tech characteristic of the product. Figure 1 (b) compares transactions prices at eBay for standard products as sold in the shop, that is, new products without any extras, with the corresponding prices from guenstiger.de, a German price comparison machine. From the graph it appears as if the guenstiger.de prices built an upper bound to the prices at eBay. The price trend is comparable.

\footnotetext{
${ }^{15}$ Caillaud and Mezzetti (2003) and Bremzen (2003) consider two-period models where bidders engage in strategic non-participation since they are reluctant to convey information to the seller respectively to a new entrant.

${ }^{16}$ See the data appendix for a detailed description on how the data was selected and cleansed.

${ }^{17}$ The information was manually retrieved from sellers' descriptions. The data appendix provides further details.
} 
Table 1: Summary Statistics of Auctions Used in Estimation

Number of auctions

Number of successful auctions

Transaction price (in $€$ ): Mean/Min-Max/Std

$469 / 280-872 / 78$

Product characteristics:

- used

- with extras

- with foreign operating system

- with defects

Auction details:

- auctions with default minimum bid $(1 €)$

- average (modus) duration of auction

In addition to the product characteristics the data contains information on auction details. eBay auctions last $3,5,7$, or 10 days. Most often sellers choose a duration of 7 days. By paying a small additional fee, the seller can raise the default minimum bid above $1 € .77 \%$ of sellers choose this option by asking on average for minimum bids in excess of $233 €$.

The data also comprises all bids that were placed in each auction together with the pseudonyms of the bidders and the bidding time. Not all bids are used for the estimation. First of all repeated bids of the same bidder in an auction are eliminated. I further use only bids which are placed towards the end as they are most likely to reflect optimal bids. ${ }^{18}$ Summary statistics of the remaining bids are given in Table 2. The bids stem from 1968 different bidders. ${ }^{19}$ On average a bidder was observed on the market for 7 days. The modus is with 2.4 hours much lower. During this time a bidder tried on average in 1.6 different auctions. Appendix B.2. shows the number of trials of a bidder in more detail. Around $30 \%$ of the bidders tried twice or more

\footnotetext{
${ }^{18}$ See the data appendix for more details and Bajari and Hortacsu (2003) for a similar approach. Whenever possible, the estimation procedure will rely on the highest observed bids only since these are the ones that are most likely to reflect bidders' optimal bids in an ascending price auction (see Haile and Tamer (2003) and Song (2004)). These are only little affected by the way the data is cleaned.

${ }^{19}$ Among them are 744 winners. Given a total of 840 auctions only very little winners thus try again. For the estimation bidders receive a new identity after winning.
} 


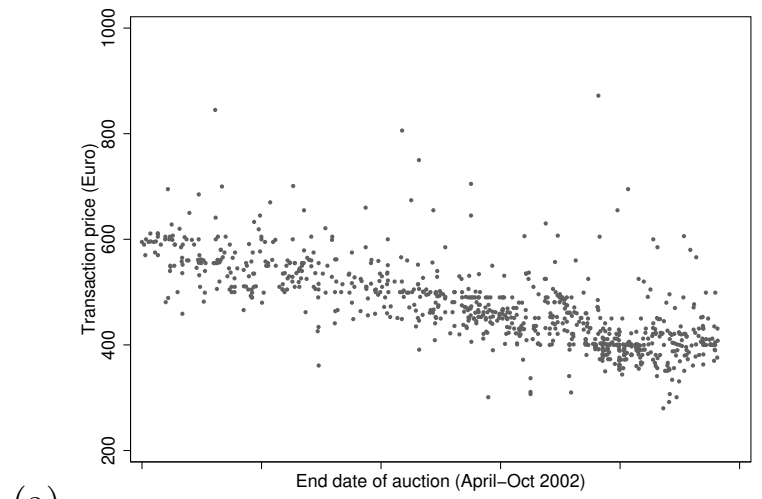

(a)

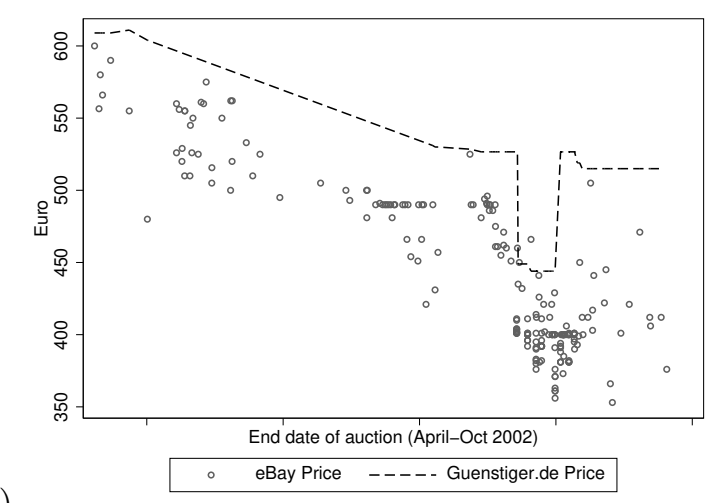

(b)

The data from guenstiger.de comprises 11 different observations for April and May and 12 observations from September to November 2002, two of which are considerably lower than the others.

Figure 1: (a) Evolution of Transaction Prices over the Course of the Sample

(b) Transaction Prices for New Products

often, up to 15 times. Simultaneous bidding in two or more auctions as well as switching back to auctions that had an earlier closing date, once a bidder is outbid in one auction, is rarely observed $(<4 \%$ of the bids).

\subsection{Evidence from Reduced Form Estimations}

To find out which of the observed variables have explanatory power, I run a simple OLS regression of bids onto product characteristics. While most of the coefficients have the expected signs, many of them do not prove significant. This holds first of all true for many of the cheaper extras such as covers, books, or protective slides which are frequently bundled with the Ipaq. Seller characteristics such as the eBay feedback scores matter but their influence is small. The results for a "parsimonious" specification which only includes the most important variables are listed in column (1) of Table 3. The negative time TREND, which was already visible in the data, is the most influential variable. Bids are also negatively affected by low product quality, assessed by the AGE of the product in days as stated by the seller or a dummy if it is not stated (AGE NA) and DEFECTS, e.g. missing standard accessory. Non-German operating systems (OS FOREIGN) decrease bids further. Additional MEMORY cards (in MB) are valued positively. Since the other extras are rarely observed, I group them: EXTRAS 1 is an indicator 
Table 2: Summary Statistics of Bidders/Bids Used in Estimation

Number of bids

Number of bidders

1968

Av. number of trials

Importance of "switching back"*

Importance of "simultaneous bidding" **

Bidder is observed in sample for:

Mean

Quantiles (25 5075$)$

0min 2.44hrs 3.98 days

Bids (in $€$ ):

Mean/Min-Max/Std. dev

$439 / 203-872 / 79$

Av. std. dev. per bidder

27.13

* Percentage of bids, placed by a bidder in an auction $\mathrm{t}$ after she was outbid in auction $\mathrm{t}+1$.

* Percentage of bids, placed by a bidder while she still had a standing bid in another auction.

for a PC Card or Bluetooth Jacket ${ }^{20}$ and for extra warranty ${ }^{21}$, EXTRAS 2 indicates a dual slot jacket and/or a microdrive ${ }^{22}$, EXTRAS 3 finally combines dummies for GSM/GPRS jackets and add-on navigation systems. All these extras are valued positively.

The data showed that there are many bidders who try in several auctions. To provide first evidence that they also have an impact on the market outcome, an indicator for the bidding strategy followed by the winner in that auction (\# TRIALS) is included into the regression. The indicator takes the values 1-15 according to the number of overall trials of a bidder. Column (2) provides the results. The parameter estimate for the indicator is significantly negative, stating that bidders who try more often bid lower.

The theoretical model finally posits a relation between supply side details and participation behavior. Here, I try to find out whether such a relation exists in the data at all and which variables drive participation.

The data appendix shows how to elicit the participation decisions from the data. From

\footnotetext{
${ }^{20}$ Jackets are plastic casings that enhance the functionality of Ipaqs by for example providing extra slots for memory cards.

${ }^{21}$ Extra warranty is called 'Carepaq' and is available for 1,2 , or 3 years.

${ }^{22}$ These are mostly in form of a 1 GB Toshiba harddisk.
} 
Table 3: OLS Estimation

\begin{tabular}{lrrrrl}
\hline & $\mathbf{( 1 )}$ & & $\mathbf{( 2 )}$ & \\
\hline CONS & 579.88 & $(2.56)$ & 587.17 & $(2.64)$ \\
TREND & -.85 & $(0.01)$ & -0.84 & $(0.01)$ \\
\# TRIALS & & & -2.72 & $(0.29)$ \\
AGE & -0.10 & $(0.01)$ & -0.10 & $(0.01)$ \\
AGE NA & -24.55 & $(2.33)$ & -22.50 & $(2.31)$ \\
OS FOREIGN & -39.11 & $(4.11)$ & -39.45 & $(4.06)$ \\
DEFECTS & -27.31 & $(4.31)$ & -28.02 & $(4.26)$ \\
MEMORY & 0.36 & $(0.02)$ & 0.36 & $(0.02)$ \\
EXTRAS 1 & 49.36 & $(4.13)$ & 49.25 & $(4.07)$ \\
EXTRAS 2 & 95.50 & $(5.57)$ & 93.97 & $(5.50)$ \\
EXTRAS 3 & 155.16 & $(6.43)$ & 152.19 & $(6.36)$ \\
\hline OBS & 3182 & & 3182 & \\
$R^{2}$ & 0.695 & & 0.703 & \\
adj $R^{2}$ & 0.694 & & 0.702 & \\
\hline
\end{tabular}

White heteroscedasticity robust estimation. Standard errors in parenthesis.

Lemma 2 it is known that a single cutoff value for the costs exists: Entry happens if $v_{i t}>g\left(\mathbf{s}_{t}, c_{i}\right)$. Since $g$ cannot be solved analytically I approximate it by a p-th order Taylor series expansion. Assuming that valuations are distributed logistically and that the interactions with $c_{i}$ are not significant, the conditional maximum likelihood estimator proposed by Andersen (1970) can be applied. ${ }^{23}$ As auction details I use the minimum bid and the duration of the auction. Further, all product characteristics from the parsimonious specification above are used as covariates.

Since most of the higher order and interaction terms were either not significant or had little explanatory power, only the coefficients of a simple linear specification are reported. Further,

Table 4: Conditional Logit Estimation

\begin{tabular}{lrr}
\hline DURATION & 0.091 & $(0.015)$ \\
MINIMUM BID & 0.003 & $(0.000)$ \\
\hline OBS & 11083 \\
$\log$ likelihood & -2923.89 \\
\hline
\end{tabular}

nearly all of the coefficients for the product characteristics are either not significant or depend

\footnotetext{
${ }^{23}$ The latter assumption is checked in the estimation by dividing the panel into sub-panels, involving different groups of individuals, which are then independently estimated by conditional logit.
} 
on the way the participation vector is constructed (see appendix). We will see later that product characteristics should be insignificant for a specific form of valuations. As for the auction details, the coefficients have the expected signs: While the duration of an auction influence the entry decision positively a high minimum bid makes it more likely that the bidder stays out. The results for this robust specification are given in Table 4 .

\section{Identification}

The structural parameters of interest in the general model considered in Subsection 2.3 are bidders' valuations for the product conditional on its characteristics and the individual bidding costs. The focus in the existing empirical work on auctions has been on the distribution of bidders' valuations. The main aim of this work is to see whether individual specific demand parameters which affect strategies when dynamic considerations are taken into account, can be identified as well when data with a panel structure is available.

In principle, all information is summarized in the distribution of the observed bids. Full information Maximum Likelihood inference, if feasible at all, would though be computationally very expensive in the current setting. Difficulties arise due to unobserved winning bids, endogenous selection, and correlation among bids of the same bidder. Further, no closed form solution exists for the value function as a function of the unobserved costs. By extending results known form the literature on estimating demand from auction data, the first set of issues can be dealt with. The problem with the unknown value function is solved when as in the literature on estimating dynamic games the full information approach is swapped for a less efficient stepwise procedure (see e.g. Bajari et al. (forthcoming) and Pakes et al. (forthcoming)). The following discussion on identification focuses on the identifying restrictions in such a stepwise approach.

Rewriting the optimality condition given in (12) for bidder i as a function of optimal bids and the optimal participation decision of bidder i and using the expectations operator gives:

$$
c_{i}=\mathbb{E}_{\mathbf{s}, b_{i}^{*}}\left[E_{b_{(1)}}\left[\mathbf{1}\left\{b_{(1)}<b_{i}^{*}\right\}\left(b_{i}^{*}-b_{(1)}\right) \mid \mathbf{s}\right] \mid \delta_{i}^{*}=1\right]
$$

Clearly, given observations on supply side characteristics s, on all bids of participants, and hence on participation decisions in case they are affirmative, bidder $i$ 's costs can be computed from (14). In principle, the behavior of all bidders as well as the product characteristics and the auction details can be observed at eBay. However, in a second price auction winning bids are 
not observable but only a lower bound to them, the transaction prices which correspond to the second highest bids. Using the observed bids would therefore bias the cost estimates. Estimates of the parent distribution(s) from which all bids ultimately are drawn can, however, be obtained from the observed bids by exploiting information contained in the ordering of the bids following methodologies developed in the empirical auctions literature. The parent distribution(s) can then be used to construct estimates of the unobserved winning bids which will be used to complete the bid data set.

Since bids of the same bidder are correlated across auctions, it has to be taken into account that the parent distributions from which bidders draw their bids conditional on a certain draw of $c$ are not identical. Identification results for likelihood inference in second price auctions with asymmetric bidders are available when the data consists of transaction prices and the identity of the winner (see Athey and Haile (forthcoming) and Brendstrup and Paarsch (2004)). These identification results can be traced back to the literature on competing risks. An insight from this literature, which becomes valuable in the asymmetric bidders' case, is that knowledge of bidders' identities eases identification (see Berman (1963) and Prakasa Rao (1992)). In the eBay setting identities and bids of all of the loosing bidders are available as well. Song (2004) points to the fact that, if lower ordered bids are observable, estimating from the distribution of the second highest bid conditional on the third highest bid allows inference without having to know the total number of bidders. Combining these two results, the following lemma can be stated:

Lemma 3. Let $X_{i}$ be independent random variables with continuous distribution functions $F_{i}$, $i=1, \ldots, n$. Denote $x_{1}, \ldots, x_{n}$ a random sample from $X_{1}, \ldots, X_{n}$.

(a) The probability distribution of the second highest order statistic $X_{(2)}$ conditional on the third highest $X_{(3)}$, when the identities of the highest observation, respectively the second and third highest, are $I_{(1)}=m, I_{(2)}=l$, and $I_{(3)}=k$, is given by:

$$
g^{n-1: n}\left(x_{(2)}, m, l \mid x_{(3)}\right)=\frac{\left(1-F_{m}\left(x_{(2)}\right)\right) f_{l}\left(x_{(2)}\right)}{\left(1-F_{m}\left(x_{(3)}\right)\right)\left(1-F_{l}\left(x_{(3)}\right)\right)}=\left(1-F_{m}\left(x_{(2)} \mid x_{(3)}\right)\right) f_{l}\left(x_{(2)} \mid x_{(3)}\right)
$$

(b) The $F_{i}(\cdot)$ are non-parametrically identified from observation of the second and third highest bids when the identities of the winner and the second highest bidder are observed as well.

Proof. See Appendix. 
In the asymmetric setting conditioning thus makes the distribution to estimate not only independent of the number of lower ordered bids but also of the distribution functions of these bidders. The distribution of the conditioning variable $y$ is irrelevant as well, what matters is its value.

Letting $F_{i}$ be the bid distribution for participating bidder $i$ we have from Lemma 3 that these are identified from eBay data. Since the common distribution of valuations only differs by an individual specific constant $V_{i}^{e}$ from the individual bid distributions, they can easily be related. However, identification is, as opposed to the static setting, only possible up to location since the common parts in $v$ and $V^{e}$ cannot be separated. Given the bid distributions, estimates of the unobserved winning bids can be build and thus the costs can be computed from (14). The following proposition summarizes the preceding discussion and presents the main identification results:

Proposition 2. Under the assumptions of the theoretical model proposed in 2.3, the following holds given eBay data:

(a) The distribution of valuations is non-parametrically identified up to location.

(b) Bidding cost are non-parametrically identified.

Proof. See Appendix.

\section{Estimation}

After having established identification, I can now come to the procedure for estimating the parameters of interest. The algorithm proceeds in steps:

1. Estimation of the observed bid distribution using information on the second and third highest bid as well as the identities of the winner and the second highest bidder.

2. Computation of the bidding costs after replacing the observed bids of the winners by estimates obtained from step 1.

Since the first step requires the unknown costs as an input, the steps have to be iterated until convergence. 


\subsection{Preliminaries: Bidder's Valuations}

While nonparametric identification is possible, the data requirements for nonparametric estimation are huge. A characterizing feature of eBay data though is that the products are normally rather heterogenous and the time dimension of the panel, that is, the number of observations per bidder, is small. Finding an expected value for each bidder and all combinations of $\mathbf{s}$ in equation (14) therefore is a limiting factor which should be considered when devising an estimation procedure. An alternative is to first homogenize the data so that the bids present bids for identical products and use the corrected data to build an expected value for $c$ as described above. This approach relies on some mild parametric assumptions.

The influence of product heterogeneity is via bidders' valuations; homogenization of the data thus starts from assumptions about the form of this dependency. To ease identification a common index assumption with additive errors is maintained:

Assumption 7. Additive Separability. Bidders' private information is composed of a common object specific component and an additive idiosyncratic part: $v_{i t}=v\left(\mathbf{x}_{t}\right)+\epsilon_{i t}$. The $\epsilon_{i t}$ 's are iid draws from $f_{\epsilon}\left(\epsilon ; 0, \sigma_{\epsilon}\right)$ and are independent of $c_{i}$.

From the additive form of the bidders' valuations it follows that product characteristics do not determine winning odds and expected returns.

Lemma 4. Under Assumption 7, the optimal entry strategy $\delta_{i t}^{*}$ and hence the entry set $D_{i t}$ as well as the optimality condition given by (12) are independent of product characteristics.

Proof. Optimal bids are now given by: $b_{i t}^{*}=v\left(\mathbf{x}_{t}\right)+\epsilon_{i t}-V_{i}^{e}$. Using these in entry condition (9) gives: $\mathbb{E}\left[\mathbf{1} \max _{j \neq i}\left\{v\left(\mathbf{x}_{t}\right)+\epsilon_{j t}-V_{j}^{e}\right\}<v\left(\mathbf{x}_{t}\right)+\epsilon_{i t}-V_{i}^{e}\right\}\left(v\left(\mathbf{x}_{t}\right)+\epsilon_{i t}-V_{i}^{e}-\max _{j \neq i}\left\{v\left(\mathbf{x}_{t}\right)+\epsilon_{j t}-\right.\right.$ $\left.\left.\left.V_{j}^{e}\right\}\right)\right] \geq c_{i}$ which readily simplifies to $\mathbb{E}\left[\mathbf{1}\left\{\max _{j \neq i}\left\{\epsilon_{j t}-V_{j}^{e}\right\}<\epsilon_{i t}-V_{i}^{e}\right\}\left(\epsilon_{i t}-V_{i}^{e}-\max _{j \neq i}\left\{\epsilon_{j t}-\right.\right.\right.$ $\left.\left.\left.V_{j}^{e}\right\}\right)\right] \geq c_{i}$. The proof for the optimality condition (12) follows along the same lines.

Firstly, the product characteristics in the selection equation can thus be ignored, that is, all bidders with draws of $\epsilon_{i t}>g_{\epsilon}\left(c_{i}, \mathbf{a}_{t}\right)$ participate. The findings from the conditional logit in section 3 corroborate this result. Secondly, for the purpose of estimation of the costs, the data can first be homogenized and then only estimates of $b_{i}^{*}-v\left(\mathbf{x}_{t}\right)$ and $\max _{j \neq i}\left\{b_{i}^{*}-v\left(\mathbf{x}_{t}\right) \mid \delta_{j}^{*}=1\right\}$ for each $\mathbf{a} \in A$ and all bidders are needed. This is advantageous since it reduces the data requirements for consistent estimation since $\operatorname{dim}(\mathbf{a})<\operatorname{dim}(\mathbf{s})$. 
In principle estimation could now start from here. Given the large number of equally important covariates as compared to the total number of observations in my specific data set, I will simplify further and use an hedonic approach for $v(\mathbf{x})$ which stipulates a simple linear relation between product characteristics $(1, \mathbf{x})=\left(1, x_{1}, \ldots, x_{K}\right)$ and bidders' valuations. Combining this with Assumption 7 it follows for the bids:

$$
b_{i t}^{*}=C O N S+\mathbf{x}_{t} \beta_{1}-V_{i}^{0}+\epsilon_{i t} \quad \text { with } C O N S=\beta_{0}-\bar{V}^{e}
$$

$\left(\beta_{0}, \beta_{1}\right)=\left(\beta_{0}, \beta_{11}, \beta_{12}, \ldots, \beta_{1 K_{x}}\right)$ collects the common parameters and $V_{i}^{0}=V_{i}^{e}-\bar{V}^{e}$ is the individual specific influence of the continuation value. In other data sets for eBay one could think of using a nonparametric approximation for the function $v(\mathbf{x})$ instead.

\subsection{Estimation of Parent Distributions and of Missing Winning Bids}

From the proof of Prop. 2 it follows that the likelihood contribution per auction is given by:

$$
\frac{f_{b_{l}}\left(b_{(2)} \mid \mathbf{x}\right)\left(1-F_{b_{m}}\left(b_{(2)} \mid \mathbf{x}\right)\right)}{\left(1-F_{b_{l}}\left(b_{(3)} \mid \mathbf{x}\right)\right)\left(1-F_{b_{m}}\left(b_{(3)} \mid \mathbf{x}\right)\right)}
$$

where $b_{(2)}$ and $b_{(3)}$ denote the observed second, respectively third highest bid and $m$ and $l$ the identities of the winner and the second highest bidder. Since auctions are independent of each other, the log likelihood just sums the individual contributions:

$$
l=\sum_{t=1}^{T} \ln \left[\frac{f_{b_{l_{t}}}\left(b_{(2), t} \mid \mathbf{x}_{t}\right)\left(1-F_{b_{m_{t}}}\left(b_{(2), t} \mid \mathbf{x}_{t}\right)\right)}{\left(1-F_{b_{l_{t}}}\left(b_{(3), t} \mid \mathbf{x}_{t}\right)\left(1-F_{b_{m_{t}}}\left(b_{(3), t} \mid \mathbf{x}_{t}\right)\right)\right.}\right]
$$

Song (2004) proposes a semi-nonparametric estimation procedure for estimation. As opposed to her case, here the parent bid distributions are bidder specific. Given the small time dimension of the panel it does not make sense to attempt a nonparametric approach. Instead, I use a normal form for the parent bid distributions. The individual parameters as well as product characteristics then only affect the mean: $f_{b_{i}}\left(b_{i} \mid \mathbf{x}\right)=N\left[\mu_{b_{i}}, \sigma\right]$ with $\mu_{b_{i}}=C O N S+\mathbf{x} \beta_{1}-V_{i}^{0}$.

Given the huge amount of bidders as compared to the number of auctions, is it not feasible to estimate the $V_{i}^{e}$ as parameters. Instead, I exploit the fact that option values are functions of the individual costs. $V_{i}^{0}$ s thus can be approximated by a polynomial in $c_{i}$. The $c_{i}$ are, however, only known at the next step. I thus start with an initial guess for these costs and then iterate this and the following steps until convergence. 
Once estimates of the parent bid distributions, $\hat{F}_{b_{i} \mid \mathbf{x}}$, are obtained, the expected winning bid of bidder $i$ in auction $\mathrm{t}$, given it is higher than the bid of the second highest bidder, is computed from:

$$
\hat{b}_{i t}^{n: n} \equiv \mathbb{E}\left[b_{i t} \mid b_{i t}>b_{(2), t}, \mathbf{x}_{t} ; \hat{F}_{b_{i} \mid \mathbf{x}}\right]=\frac{1}{1-\hat{F}_{b_{i}}\left(b_{(2), t} \mid \mathbf{x}_{t}\right)} \int_{b_{(2), t}}^{\infty} b_{i t} d \hat{F}_{b_{i}}\left(b_{i t} \mid \mathbf{x}_{t}\right)
$$

These estimates replace in the following the truncated winning bids.

\subsection{Computation of Bidding Costs}

From Lemma 4 we know that the optimality condition is independent of product characteristics. What matters, however, are the auction details. The conditional logit estimation identified the duration of an auction and the minimum bid as the major factors influencing participation. My eBay data is not rich enough to offer enough observations for each bidder so that the individual beliefs for the error term conditional on all combinations of these auction details can be elicited from the data to build the expectation in equation (14) correctly. I thus have to ignore the weighting by auction details. The error due to this simplification is alleviated by the fact, that the highest bid of the competitors will be affected by this simplification in a similar way. ${ }^{24} \mathrm{~A}$ Monte Carlo study could help to assess how big the remaining mistake is. This is deferred to future research.

\subsection{Alternative Approaches}

Due to data limitations, distributional assumption were made in the prior estimation procedure for the bid distribution (Specification 1a). Further, the likelihood estimation depends on the incidental parameter $c_{i}$ and could for that reason provide inconsistent estimates. In this section, I will introduce some other specifications which should be seen as a robustness check on the results.

To circumvent the incidental parameters problem I use the observed number of trials of a bidder instead of the cost estimates to approximate the $V_{i}^{e}$ in the likelihood (specification (1b)). The two variables are correlates since the trials are a function of the costs: bidders with lower costs will in expectation try more often until they win a product than those with higher costs.

\footnotetext{
24 "Linear effects" would just be differenced away, following the same logic as, when arguing, in the proof to Lemma 4, that product characteristics are irrelevant.
} 
Secondly, since at eBay all lower bids are observed as well, the winning bids usually only present a small share. It would thus be interesting to check whether ignoring the problem of the truncated winning bids has a major impact on the results at all (Specification 3).

Finally, additional price data can be used (Specification 2). The data description showed that the prices from guenstiger.de built an upper bound to the prices at eBay. Assuming that a bidder always prefers to buy at guenstiger.de when the prices are equal, a value in between the guenstiger.de prices and the transaction prices can be used as an estimate for the unobserved winning bids. The drawback of this approach is that normally one will not have price data for all additional extras that are bundled with the eBay products and certainly will not have external information on the discount attached to used products or products with defects. If one is willing to assume that the relative prices between additional features and the basic product are the same for eBay and guenstiger.de, fictional prices for guenstiger.de-prices for extras can be computed by multiplying the eBay.de average price for extras - represented e.g. by the OLS regression coefficients times the value of the variable - with the ratio of the average observed guenstiger.de price and the average eBay transaction price for standard new products.

As opposed to specifications 1, specification 2 and 3 do not provide estimates of bidders' valuations. To be able to homogenize the data, thus, an additional step is required. Standard panel methods, such as first differencing, can be applied in principle. A difficulty arises through the participation decision which causes that only selected bids of a bidder can be observed. It is therefore necessary to distinguish the latent data, in the following denoted by an asterisk, from the observed data (without asterisk). The bid equation (16) in its difference form now writes as:

$$
\begin{array}{r}
b_{i t}-b_{i, t-1}=\delta_{i t} b_{i t}^{*}-\delta_{i, t-1} b_{i, t-1}^{*}=\left(\delta_{i t}-\delta_{i, t-1}\right) C O N S+\left(\delta_{i t} \mathbf{x}_{t}-\delta_{i, t-1} \mathbf{x}_{t-1}\right) \beta_{1}- \\
-\left(\delta_{i t}-\delta_{i, t-1}\right) V_{i}^{0^{*}}+\delta_{i t} \epsilon_{i t}^{*}-\delta_{i, t-1} \epsilon_{i, t-1}^{*}
\end{array}
$$

Since $\delta$ is always one when observed and since the product characteristics are not affected by the participation decision, the equation simplifies to:

$$
b_{i t}-b_{i, t-1}=\left(\mathbf{x}_{t}-\mathbf{x}_{t-1}\right) \beta_{1}+\delta_{i t} \epsilon_{i t}^{*}-\delta_{i, t-1} \epsilon_{i, t-1}^{*}
$$

Lets first look at the case when only the product characteristics but not the auction details change over time (Specification a). While $\mathbb{E}\left[\epsilon_{i t}^{*} \mid \delta_{i t}=1, \delta_{i, t-1}=1\right]$ is not zero, it is equal to 
$\mathbb{E}\left[\epsilon_{i, t-1}^{*} \mid \delta_{i, t-1}=1, \delta_{i t}=1\right]$ for all differences of bids of the same bidder and thus falls out. The parameter vector $\beta_{1}$ therefore can be consistently estimated by OLS from (21).

The more general case is when the participation decision responds to auction covariates. Now, the parameters $\gamma$ from the participation equation which has been estimated before (coefficients of the conditional logit estimation in Section 3 ) are used as described in Kyriazidou (1997) to construct weights (Specification b). These weights are used in the OLS estimation of the first differenced bid data to over-represent differences that are based on the same underlying explanatory variables for participation and to under-represent the others. The idea is that when the exogenous variables explaining selection are the same, the selection bias is the same and can be differenced out. The parameter vector $\beta_{1}$ is now estimated by OLS from:

$$
\Delta b_{i t} \sqrt{K\left(\frac{\Delta \mathbf{a}_{t} \gamma}{h}\right)}=\Delta x_{t} \sqrt{K\left(\frac{\Delta \mathbf{a}_{t} \gamma}{h}\right)} \beta_{1}+\Delta \epsilon_{i t}
$$

where $K(\cdot)$ denotes a kernel density and $\mathrm{h}$ the bandwidth of data to be included.

After homogenizing the data, the bidding costs can be computed as described before.

\section{$6 \quad$ Results}

\subsection{Bidders' Valuations for Product Characteristics}

Table 5 (1a) reports the results from the estimation of the bid distribution by conditional order statistics distributions. Since only those auctions where at least three bidders placed bids can be used for the estimation, the number of auctions in the sample reduces to $537 .^{25}$

As an approximation to the value function I use a second order Taylor approximation in the costs. $a_{1}$ and $a_{2}$ report the estimated coefficients. As expected the continuation value decreases in the cost estimate. The second order coefficient is not significant in this specification.

Due to the normal form of the parent bid distribution the remaining estimates directly describe bidders' valuations. Not much can be said about the constant of the distribution of valuations, only that it is above $557.86 €$, since the estimated constant subsumes the constant part of the valuations and of the continuation values. The standard deviation of the distribution is estimated at $51.40 €$.

\footnotetext{
${ }^{25}$ One-time bidders are given the same identity in specification 2 and 3 since otherwise I would loose the larger part of the data when first differencing. To keep results comparable, I do the same for bidders in specification 1.
} 
Table 5: Bid distribution

\begin{tabular}{|c|c|c|c|c|c|c|}
\hline & (1a) & (1b) & $(2 a)$ & $(2 \mathrm{~b})$ & $(3 a)$ & $(3 \mathrm{~b})$ \\
\hline CONS & $\begin{array}{c}557.86 \\
(13.64)\end{array}$ & $\begin{array}{c}558.67 \\
(24.23)\end{array}$ & & & & \\
\hline TREND & $\begin{array}{l}-1.36 \\
(0.09)\end{array}$ & $\begin{array}{r}-0.89 \\
(0.10)\end{array}$ & $\begin{array}{r}-0.73 \\
(0.03)\end{array}$ & $\begin{array}{r}-0.51 \\
(0.10)\end{array}$ & $\begin{array}{r}-0.78 \\
(0.03)\end{array}$ & $\begin{array}{l}-0.66 \\
(0.10)\end{array}$ \\
\hline AGE & $\begin{array}{r}-0.02 \\
(0.07)\end{array}$ & $\begin{array}{r}-0.02 \\
(0.07)\end{array}$ & $\begin{array}{r}-0.10 \\
(0.02)\end{array}$ & $\begin{array}{r}-0.12 \\
(0.02)\end{array}$ & $\begin{array}{r}-0.11 \\
(0.02)\end{array}$ & $\begin{array}{l}-0.13 \\
(0.02)\end{array}$ \\
\hline AGE NA & $\begin{array}{r}-30.01 \\
(13.53)\end{array}$ & $\begin{array}{r}-20.09 \\
(7.44)\end{array}$ & $\begin{array}{c}-18.64 \\
(3.07)\end{array}$ & $\begin{array}{c}-22.16 \\
(5.35)\end{array}$ & $\begin{array}{c}-19.62 \\
(2.87)\end{array}$ & $\begin{array}{c}-22.68 \\
(5.88)\end{array}$ \\
\hline DEFECTS & $\begin{array}{r}-24.45 \\
(26.60)\end{array}$ & $\begin{array}{r}-23.49 \\
(64.99)\end{array}$ & $\begin{array}{c}-23.14 \\
(5.85)\end{array}$ & $\begin{array}{r}-17.10 \\
(7.32)\end{array}$ & $\begin{array}{c}-23.60 \\
(5.60)\end{array}$ & $\begin{array}{r}-16.95 \\
(6.64)\end{array}$ \\
\hline OS FOREIGN & $\begin{array}{r}-33.56 \\
(19.51)\end{array}$ & $\begin{array}{c}-32.84 \\
(30.81)\end{array}$ & $\begin{array}{r}-33.00 \\
(6.03)\end{array}$ & $\begin{array}{c}-11.69 \\
(6.41)\end{array}$ & $\begin{array}{c}-32.48 \\
(5.76)\end{array}$ & $\begin{array}{r}-16.90 \\
(5.97)\end{array}$ \\
\hline MEMORY & $\begin{array}{r}0.55 \\
(0.12)\end{array}$ & $\begin{array}{r}0.79 \\
(0.18)\end{array}$ & $\begin{array}{l}-0.32 \\
(0.04)\end{array}$ & $\begin{array}{r}0.30 \\
(0.08)\end{array}$ & $\begin{array}{r}0.32 \\
(0.04)\end{array}$ & $\begin{array}{l}-0.34 \\
(0.09)\end{array}$ \\
\hline EXTRAS 1 & $\begin{array}{r}39.36 \\
(20.38)\end{array}$ & $\begin{array}{r}39.27 \\
(32.73)\end{array}$ & $\begin{array}{r}39.06 \\
(6.51)\end{array}$ & $\begin{array}{r}27.22 \\
(12.42)\end{array}$ & $\begin{array}{c}39.67 \\
(6.27)\end{array}$ & $\begin{array}{c}28.17 \\
(11.90)\end{array}$ \\
\hline EXTRAS 2 & $\begin{array}{c}106.16 \\
(27.45)\end{array}$ & $\begin{array}{c}106.21 \\
(35.58)\end{array}$ & $\begin{array}{c}106.21 \\
(10.47)\end{array}$ & $\begin{array}{r}109.72 \\
(10.04)\end{array}$ & $\begin{array}{r}101.31 \\
(9.50)\end{array}$ & $\begin{array}{l}130.76 \\
(13.03)\end{array}$ \\
\hline EXTRAS 3 & $\begin{array}{c}149.46 \\
(35.52)\end{array}$ & $\begin{array}{r}185.87 \\
(36.61)\end{array}$ & $\begin{array}{c}147.74 \\
(9.22)\end{array}$ & $\begin{array}{r}181.32 \\
(9.75)\end{array}$ & $\begin{array}{r}147.92 \\
(14.31)\end{array}$ & $\begin{array}{l}157.71 \\
(15.45)\end{array}$ \\
\hline$a_{1}$ & $\begin{array}{r}-2.20 \\
(0.38)\end{array}$ & $\begin{array}{r}25.81 \\
(7.12)\end{array}$ & & & & \\
\hline$a_{2}$ & $\begin{array}{c}-0.01 \\
(0.01)\end{array}$ & $\begin{array}{l}-0.51 \\
(0.15)\end{array}$ & & & & \\
\hline OBS & 537 & 537 & 2602 & 2602 & 2602 & 2602 \\
\hline log likelihood & -2337.60 & -2314.18 & & & & \\
\hline$R^{2}$ & & & 0.457 & 0.721 & 0.528 & 0.771 \\
\hline adj. $R^{2}$ & & & 0.456 & 0.720 & 0.526 & 0.771 \\
\hline$\sigma$ & 51.40 & 62.26 & 55.35 & 54.74 & 49.55 & 46.80 \\
\hline
\end{tabular}

The negative time trend indicates that over time the valuations for the product decrease. As already mentioned, this is due to the high tech characteristic of the product. Age, defects, and a foreign operating system have a negative effect on the valuation while additional extras positively impact on the bidders' willingness to pay. The relative importance of the different extras reflects their relative prices outside eBay. Since the average age of a product in the sample is 65 days, bidders either overestimate the age or presume, that it will be older than average, when the seller does not specify it in the description given the coefficient estimate for AGE NA.

The estimated winning bids in those auctions where the winning bids exceeded the reserve are on average $21.62 €$ higher than the transaction prices. This is money which was left on the 
table and could have been appropriated by the sellers by setting high enough minimum bids.

Column 2 gives the results for the order statistics estimation where the individual effects are approximated by the number of trials. Here the estimate for $a_{2}$ is significant; its negative sign shows that he value function is concave, as expected. While most of the other coefficients are comparable, the differing estimate for the TREND indicates that there is an incidentals parameters problem in the estimation of specification (1a).

Columns 3 to 6 report the corresponding results for the alternative specifications which mostly corroborate the previous results: Most of the estimated coefficients for product characteristics are not significantly different. The most important difference lays in the estimate of the variable AGE which only here is significant and has a considerably higher impact. The choice of the panel method, with or without weighting, matters more for the results than which method is used to substitute for the unknown winning bids. Simple first differences without correcting for missing winning bids give already quite good approximations to the true results.

The results for estimation (2b) and (3b) should be interpreted with caution, however, since they are highly dependent on the choice of the initial bandwidth constant. This is a problem which has already been noticed by Kyriazidou (1997). The choice of the form of the kernel matters less. Here I choose a bandwidth of 50 with a kernel of order 5 .

\subsection{Bidding Costs}

The average cost of a bidder at eBay, using Specification (1a), is estimated at $13.19 €$ which is equivalent to $2.8 \%$ of the average transaction price. The corresponding frequency distribution is displayed in figure 2. The distribution is highly skew, the median bidder has a cost of only $9.02 €$. The standard deviation of a bidder's costs from the mean bidder's costs is estimated at $13.62 €$.

In figure 3 kernel densities of the costs for all different specifications are plotted. We have seen in the last paragraph that the estimates for valuations for product characteristics differ only little among the different specifications. The shapes of the different cost distributions are similar as well. As opposed to the valuations here the way the bids are imputed matters more than what kind of methodology is used to homogenize the data in specification (2a)-(3b). Again, simple first differences already provide good approximations to the true estimates. The most significant difference is in the distributions from specification (1a) and (1b). The latter leads 
Figure 2: Frequency of Bidding Costs (Specification 1a)

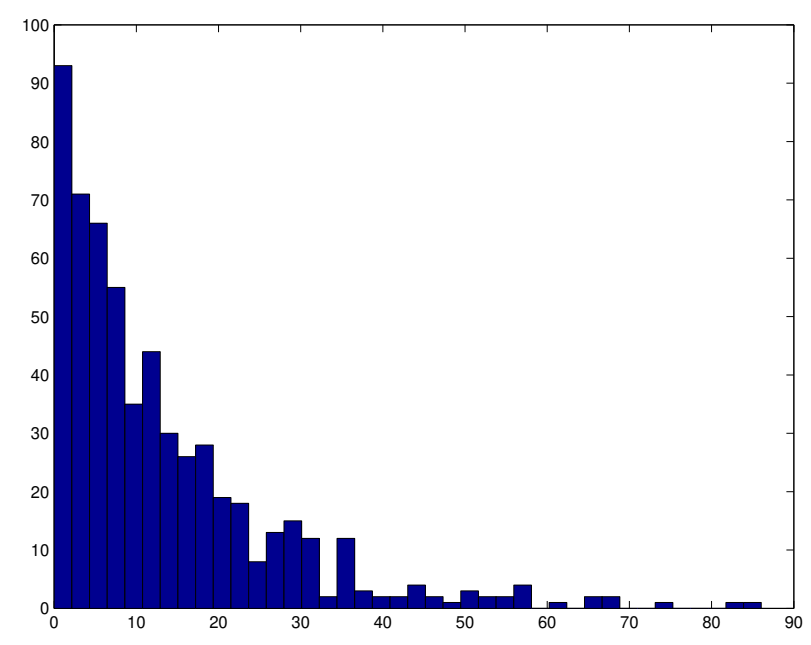

to median cost estimates of only $3.82 €$. The higher standard deviation of specification (1a) as opposed to (1b) is, on the other hand, matched by a lower estimate for the standard deviation of the valuations.

\section{Conclusion}

The paper presented a dynamic framework for the eBay marketplace, similar to a search model. It was shown that a stepwise estimation approach can be used to estimate demand parameters from eBay bidding data. While costs and valuations are nonparametrically identified, the huge amount of covariates asks for parametric assumptions in the estimation process. The small time dimension of the panel requires further simplifications.

The main insights from the paper are that applying a search strategy gives the bidder the product for a lower price than when ignoring future options $(b \neq v)$. Observed price dispersion at Internet auctions can be attributed to such a behavior. Alternative methods can be used to estimate bidding costs all leading to reasonable estimates which are much lower than those which have been estimated in the literature so far.

A number of issues remains for future research. First of all, the seller side so far is modelled rather crudely. Further, the theoretical model assumed that in every instant a new auction opens and bidders do not care whether the time difference between the auctions is small or big. Including parameters for the degree of competition from other auctions into the theoretical 
Figure 3: Kernel Densities and Statistics of Bidding Costs for Different Specifications

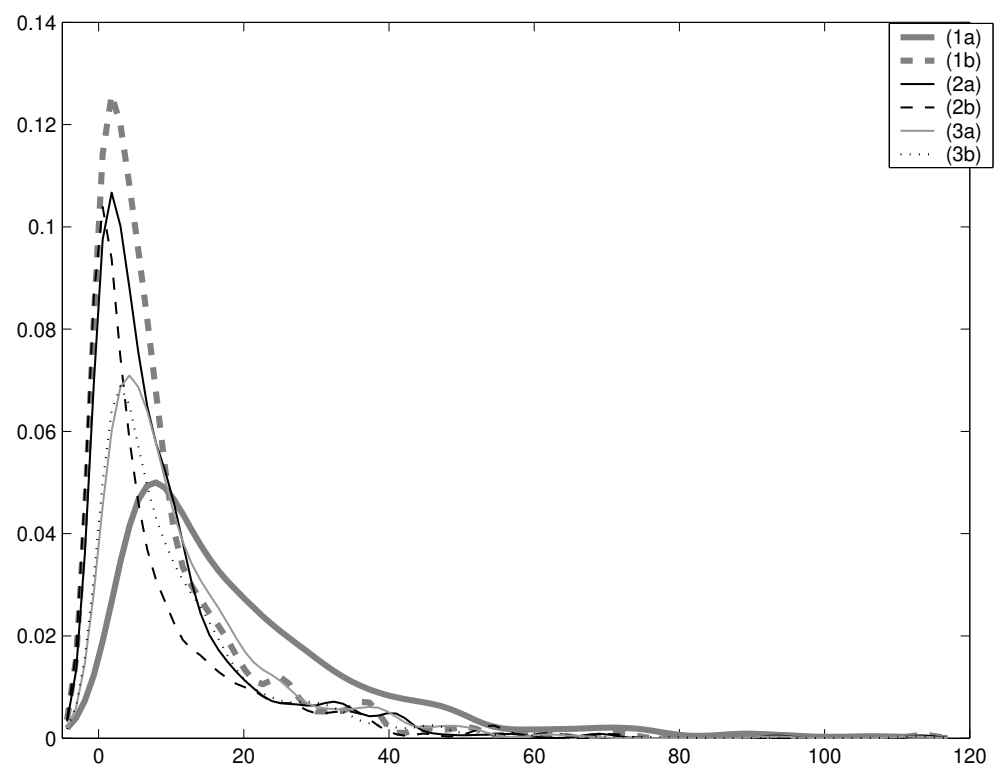

\begin{tabular}{lrllrrr}
\hline & $(1 \mathrm{a})$ & $(1 \mathrm{~b})$ & $(2 \mathrm{a})$ & $(2 \mathrm{~b})$ & $(3 \mathrm{a})$ & $(3 \mathrm{~b})$ \\
\hline Mean & 13.19 & 6.27 & 7.20 & 8.91 & 10.03 & 10.97 \\
Median & 9.02 & 3.82 & 4.28 & 4.31 & 6.60 & 7.06 \\
Std & 13.62 & 7.51 & 8.85 & 11.98 & 10.61 & 12.14 \\
Min-Max & $0-84$ & $0-76$ & $0-84$ & $0-107$ & $0-95$ & $0-113$ \\
\hline
\end{tabular}

model would be desirable.

Secondly, when deriving the theoretic model it was assumed, the characteristics of potential bidders are given exogenously and stay constant over time. Relaxing this assumption could lead to more sophisticated dynamic strategies which include predation and strategic nonparticipation. While I do not believe that this would add much explanation to the data generation process in markets for standardized products, it might play a role in thin markets and is interesting from a theoretical perspective.

Finally, assuming, bidders exactly know the distribution of their competitor's bids, is asking a lot of a bidder. While here it was assumed that bidders exactly know the distribution, Sailer (2005) allows for the possibility of learning about a parameter of the distribution of second highest bid. 


\section{References}

Albrecht, James W. and Bo Axell, "An Equilibrium Model of Search Unemployment," Journal of Political Economy, October 1984, 92 (5), 824-40.

Andersen, Erling Bernhard, "Asymptotic Properties of Conditional Maximum-likelihood Estimators.," Journal of the Royal Statistical Society, Series B, 1970, 32 (2), 283-301.

Athey, Susan and Philip A. Haile, "Identification of Standard Auction Models," Econometrica, November 2002, 70 (6), 2107-40.

and __ "Nonparametric Approaches to Auctions," in "Handbook of Econometrics" forthcoming.

Bajari, Patrick and Ali Hortacsu, "The Winner's Curse, Reserve Prices, and Endogenous Entry: Empirical Insights from eBay Auctions," RAND Journal of Economics, Summer 2003, 34 (2), 329-55.

, Lanier Benkard, and Jonathan Levin, "Estimating Dynamic Models of Imperfect Competition," Econometrica, forthcoming.

Berman, Simeon M., "Note on extreme values, competing risks and semi-Markov processes," Ann. Math. Statist., 1963, 34 (3), 1104-1106.

Bremzen, Andrei, "Sequential Auctions with Entry Deterrence," mimeo, 2003, (November).

Brendstrup, Bjarne and Harry J. Paarsch, "Identification and Estimation in Sequential, Asymmetric, English Auctions," Typescript. Iowa City, Iowa: Department of Economics, University of Iowa, 2004.

Burdett, Kenneth and Dale T. Mortensen, "Wage Differentials, Employer Size, and Unemployment," International Economic Review, May 1998, 39 (2), 257-73.

Caillaud, Bernard and Claudio Mezzetti, "Equilibrium Reserve Prices in Sequential Ascending Auctions," mimeo, 2003, (May).

David, H. A. and H. N. Nagaraja, Order Statistics, Wiley-Interscience, 2003. 
Diamond, Peter, "A Model of Price Adjustment," Journal of Economic Theory, 1971, 3, $156-168$.

Gal, Shmuel, Michael Landsberger, and Arkadi Nemirovski, "Participation in Auctions," mimeo, 2004, (November).

Guerre, Emmanuel, Isabelle Perrigne, and Quang Vuong, "Optimal Nonparametric Estimation of First-Price Auctions," Econometrica, May 2000, 68 (3), 525-74.

Haile, Philip and Elie Tamer, "Inference with an Incomplete Model of English Auctions," Journal of Political Economy, 2003, 111 (1), 1-50.

Hendricks, K. and R.H. Porter, "Lectures on Auctions: An Empirical Perspective," in "Handbook of Industrial Organization" forthcoming.

Hong, Han and Matthew Shum, "Using Price Distributions to Estimate Search Costs.," RAND Journal of Economics, 2006, 37 (2).

Hortacsu, Ali and Chad Syverson, "Product Differentiation, Search Costs, and Competition in the Mutual Fund Industry: A Case Study of S\&P 500 Index Funds," Quarterly Journal of Economics, May 2004, 119 (2), 403-56.

Houser, Dan and John Wooders, "Reputation in Auctions: Theory, and Evidence from eBay," Journal of Economics and Management Strategy, forthcoming.

Jin, Ginger Z. and Andrew Kato, "Price, Quality and Reputation: Evidence From An Online Field Experiment," forthcoming.

Jofre-Bonet, Mireia and Martin Pesendorfer, "Estimation of a Dynamic Auction Game," Econometrica, September 2003, 71 (5), 1443-89.

Kyriazidou, Ekaterini, "Estimation of a Panel Data Sample Selection Model," Econometrica, November 1997, 65 (6), 1335-64.

Laffont, Jean Jacques and Quang Vuong, "Structural Analysis of Auction Data," American Economic Review, May 1996, 86 (2), 414-20. 
Lucking-Reiley, David, Doug Bryan, Naghi Prasad, and Daniel Reeves, "Pennies from eBay: the Determinants of Price in Online Auctions," Journal of Industrial Economics, forthcoming.

Pakes, Ariel, Michael Ostrovsky, and Steve Berry, "Simple Estimators for the Parameters of Discrete Dynamic Games (with Entry / Exit Examples)," RAND Journal of Economics, forthcoming.

Rao, B.L.S. Prakasa, "Identifiability in Stochastic Models. Characterization of Probability Distributions.," in "in" Probability and Mathematical Statistics, Boston et al.: Harcourt Brace Jovanovich Publishers, 1992.

Rob, Rafael, "Equilibrium Price Distributions," Review of Economic Studies, July 1985, 52 (3), 487-504.

Roth, Alvin E. and Axel Ockenfels, "Last-Minute Bidding and the Rules for Ending SecondPrice Auctions: Evidence from eBay and Amazon Auctions on the Internet," American Economic Review, September 2002, 92 (4), 1093-1103.

Sailer, Katharina, "Bayesian Learning at eBay? Updating from related data and empirical evidence.," mimeo, 2005, (August).

Song, Unjy, "Nonparametric Estimation of an eBay Auction Model with an Unknown Number of Bidders," mimeo, 2004, (January).

Sorensen, Alan T., "An Empirical Model of Heterogeneous Consumer Search for Retail Prescription Drugs," NBER Working Paper, October 2001, 8548.

van den Berg, Gerard J. and Geert Ridder, "An Empirical Equilibrium Search Model of the Labor Market," Econometrica, September 1998, 66 (5), 1183-1221.

von der Fehr, Nils Henrik Morch, "Predatory Bidding in Sequential Auctions," Oxford Economic Papers, July 1994, 46 (3), 345-56.

Weber, Robert J., "Multiple-Object Auctions," in Paul Klemperer, ed., The economic theory of auctions, VOL 2, Cheltenham, UK and Northampton, MA: Elgar, 2000, pp. 240-66. 
Wiggans, Richard Engelbrecht, "Sequential Auctions of Stochastically Equivalent Objects," Economics Letters, 1994, 44 (1-2), 87-90.

yi Wang, Joseph Tao, "Is Last Minute Bidding Bad?," mimeo, 2003, (September).

Zeithammer, Robert, "Forward-looking Bidding in Online Auctions," Journal of Marketing Research, 43, 462-476. 


\section{Appendix: Proofs}

Proof of Proposition 1.

\section{(a) Optimal Bid:}

Exploiting the fact that loosing is complementary to winning the decision problem of a participating bidder given in equation (6) can be rewritten as:

$$
V_{i}=\max _{b_{i}>r} \mathbb{E}_{b_{(1)}}\left[\mathbf{1}\left\{b_{(1)}<b_{i}\right\}\left(v_{i}-V_{i}^{e}-b_{(1)}\right) \mid \mathbf{s}\right]-c_{i}+V_{i}^{e} .
$$

The proof of optimality of the bid is then a simple application of the proof for a standard second price auction with valuation $y=v-V^{e}$. (The additional constant $-c_{i}+V_{i}^{e}$ influences neither the price nor the winning probability and is thus irrelevant for the bidding strategy.)

\section{(b) Distribution of the Maximum:}

Computation of the distribution of the maximum as a function of the underlying distribution of competitors' characteristics is complicated by the two-dimensional uncertainty - about $v_{j}$ and $c_{j}$ - and by the two-stage decision process - first compute the optimal bid, then decide whether to participate with this bid or not. Following Gal, Landsberger and Nemirovski (2004), I will collapse the two-stage decision on the side of the competitors into one by assuming, a nonparticipating bidder places a bid $b_{\text {low }}{ }^{26}$ which is too low to have any winning chances. For this purpose the new random variable:

$$
\tilde{b}^{*}= \begin{cases}b_{\text {low }} & \text { if } \delta^{*}=0 \\ b^{*} & \text { if } \delta^{*}=1\end{cases}
$$

is introduced. The highest bid out of the $m-1$ competitors' bids in auction $t$ is now denoted by $\tilde{b}_{h t}^{*} \equiv \max _{j \neq i}\left\{\tilde{b}_{j t}^{*}\right\}$. Since $b_{h t}^{*}=\tilde{b}_{h t}^{*}$ for all $\nu$ and $\mathbf{s}$, building the expectation with respect to the random variable $\tilde{b}^{*}$ is equivalent to using $b^{*} \delta^{*}$ conditional on $\delta^{*}=1$. The advantage of the former is that it allows to express the distribution of the maximum in each period as a function of the potential number of competitors; only its shape and the support potentially change with changes in the expected participation decisions.

\footnotetext{
${ }^{26}$ Since in the next subsection, by definition, the lowest bid has to be strictly higher than the reserve, I can let $b_{\text {low }}=r$.
} 
Given participation is optimal from equation (6) it holds for bidder i:

$$
\begin{array}{r}
V_{i}(\cdot)=\max _{b_{i}>r} \mathbb{E}\left[\mathbf{1}\left\{\max _{j \neq i}\left\{b\left(\nu_{j}, \mathbf{s}\right) \mid \delta\left(\nu_{j}, \mathbf{s}\right)=1\right\}<b_{i}\right\}\left(v_{i}-V_{i}^{e}-\max _{j \neq i}\left\{b\left(\nu_{j}, \mathbf{s}\right) \mid \delta\left(\nu_{j}, \mathbf{s}\right)=1\right\}\right) \mid \mathbf{s}\right]- \\
-c_{i}+V_{i}^{e} .
\end{array}
$$

Now build the expectation with respect to the unknown variables $\nu_{-i}$ :

$$
\begin{array}{r}
V_{i}(\cdot)=\max _{b_{i}>r} \int_{\underline{c}}^{\bar{c}} \ldots \int_{\underline{c}}^{\bar{c}} \int_{\underline{v}(\mathbf{x})}^{\bar{v}(\mathbf{x})} \ldots \int_{\underline{v}(\mathbf{x})}^{\bar{v}(\mathbf{x})} \mathbf{1}\left\{\max _{j \neq i}\left\{b\left(\nu_{j}, \mathbf{s}\right) \mid \delta\left(\nu_{j}, \mathbf{s}\right)=1\right\}<b_{i}\right\} . \\
\cdot\left(v_{i}-V_{i}^{e}-\max _{j \neq i}\left\{b\left(\nu_{j}, \mathbf{s}\right) \mid \delta\left(\nu_{j}, \mathbf{s}\right)=1\right\}\right) d F_{\nu_{-i}}\left(\nu_{-i} \mid \mathbf{x}\right)-c_{i}+V_{i}^{e} .
\end{array}
$$

While the competitors' bids are functions of both the costs and the valuations, the entry set $D_{j}$, which gives all $v$ for which a bidder with $\operatorname{costs} c_{j}$ enters, is a function of the costs alone. To apply a change of variables it is therefore necessary to first condition on the unknown costs and then to change the variable of integration to $b_{j}^{*}$. The conditioning brings about that the variables of interest, namely the bids of the competitors, are now drawn from different distributions. The distribution of the maximum of $m-1$ non-identically but independently drawn variables distributed according to $f_{j}$ with cdf $F_{j}$ is given by $f^{m-1: m-1}(b)=\left[\Pi_{j=1}^{m-1} F_{j}(b)\right] \sum_{j=1}^{m-1}\left(\frac{f_{j}(b)}{F_{j}(b)}\right)$ (see David and Nagaraja (2003, p 96)) or $f^{(m-1)}(b)=\sum_{i=1}^{m-1} f_{i}(b) \prod_{\substack{j=1 \\ j \neq i}}^{m-1} F_{j}(b)$. Finally, from transformation techniques we know that the distribution of a variable $y=g(x)$ where $x$ is a continuous variable with pdf $f_{x}$ which is non-zero for $x \in \mathcal{X}$ and $y$ a one-to-one transformation of $\mathcal{X}$ onto $\mathcal{Z}$ is given by $f_{y}(y)=\left|\frac{d}{d y} g^{-1}(y)\right| f_{x}\left(g^{-1}(y)\right) \mathbf{1}(y \in \mathcal{Z})$. For $v \in D_{j}$ and $V_{j}^{e}$ a known constant the function $\tilde{b_{j}}=v-V_{j}^{e}$ is continuous and one-to-one; hence $f_{b}\left(b_{j}^{*} \mid c_{j}, \mathbf{x}\right)=f_{v}\left(b_{j}^{*}+\right.$ $\left.V_{j}^{e} \mid \mathbf{x}\right) \mathbf{1}\left\{b_{(1)}+V_{j}^{e} \in D_{j}\right\}$. The rest of the probability mass, that is when $v \notin D_{j}$, is concentrated at $b_{\text {low }}$. Since $b_{\text {low }}$ by assumption does not influence neither the price nor the winning probability it is irrelevant for the computation of the distribution of the maximum. It then follows for the bidders' problem:

$$
V_{i}(\cdot)=\max _{b_{i} \geq r} \int_{\tilde{b}_{h}^{*}<b_{i}}\left(v_{i}-V_{i}^{e}-\tilde{b}_{h}^{*}\right) \int_{\underline{c}}^{\bar{c}} \ldots \int_{\underline{c}}^{\bar{c}} f_{\tilde{b}}^{h}\left(\tilde{b}_{h}^{*}, \mathbf{c}_{-i} \mid \mathbf{s}\right) d \mathbf{c}_{-i} d \tilde{b}_{h}^{*}-c_{i}+V_{i}^{e}
$$

with

$$
f_{\tilde{b}}^{h}\left(\tilde{b}_{h}^{*}, \mathbf{c}_{-i} \mid \mathbf{s}\right)=\sum_{j=1}^{m-1} f_{v}\left(\tilde{b}_{h}^{*}+V_{j}^{e} \mid \mathbf{x}\right) \mathbf{1}\left\{\tilde{b}_{h}^{*}+V_{j}^{e} \in D_{j}\right\} f_{c}\left(c_{j}\right) \prod_{\substack{k=1 \\ k \neq j}}^{m-1} \int_{\substack{z \in D_{k}, z<\tilde{b}_{h}^{*}+V_{k}^{e}}} d F_{v}(z \mid \mathbf{x}) f_{c}\left(c_{k}\right) .
$$

Since $\int_{\underline{c}}^{\bar{c}} f_{v}\left(\tilde{b}_{h}^{*}+V_{j}^{e} \mid \mathbf{x}\right) \mathbf{1}\left\{\tilde{b}_{h}^{*}+V_{j}^{e} \in D_{j}\right\} d F_{c}\left(c_{j}\right)=\int_{\underline{c}}^{\bar{c}} f_{v}\left(\tilde{b}_{h}^{*}+V_{k}^{e} \mid \mathbf{x}\right) \mathbf{1}\left\{\tilde{b}_{h}^{*}+V_{k}^{e} \in D_{k}\right\} d F_{c}\left(c_{k}\right)$ we 
can also write

$$
\begin{aligned}
& f_{\tilde{b}}^{h}\left(\tilde{b}_{h}^{*} \mid \mathbf{s}\right)= \int_{\underline{c}}^{\bar{c}} \ldots \int_{\underline{c}}^{\bar{c}} f_{\tilde{b}}^{h}\left(\tilde{b}_{h}^{*}, \mathbf{c}_{-i} \mid \mathbf{s}\right) d \mathbf{c}_{-i} \\
&=(m-1) \int_{\underline{c}}^{\bar{c}} f_{v}\left(\tilde{b}_{h}^{*}+V^{e} \mid \mathbf{x}\right) \mathbf{1}\left\{\tilde{b}_{h}^{*}+V^{e} \in D(c, \mathbf{s})\right\} d F_{c}(c) . \\
& \\
& \cdot\left(\int_{\underline{c}}^{\bar{c}} \int_{\substack{z \in D(c, \mathbf{s}), z<\tilde{b}_{h}^{*}+V^{e}}} d F_{v}(z \mid \mathbf{x}) d F_{c}(c)\right)^{m-2}
\end{aligned}
$$

which is non-degenerate.

Proof of Lemma 2. Let

$$
F_{\tilde{b}}^{h}\left(b^{*} \mid \mathbf{s}\right) \equiv \int_{\underline{c}}^{\bar{c}} \ldots \int_{\underline{c}}^{\bar{c}} \int_{\tilde{b}_{h}^{*}<b_{i}} f_{\tilde{b}}^{h}\left(\tilde{b}_{h}^{*}, \mathbf{c}_{-i} \mid \mathbf{s}\right) d \tilde{b}_{h}^{*} \mathbf{d} \mathbf{c}_{-i}
$$

where $f_{\tilde{b}}^{h}$ as defined in the Proof to Prop.1 and

$$
\mathbb{E}\left[\tilde{b}_{h}^{*} \mid \tilde{b}_{h}^{*}<b^{*}, \mathbf{s}\right] \equiv \int_{\underline{c}}^{\bar{c}} \ldots \int_{\underline{c}}^{\bar{c}} \int_{b_{(1)}<b_{i}} b_{(1)} f_{b}^{h}\left(b_{(1)}, \mathbf{c}_{-i} \mid \mathbf{s}\right) d b_{(1)} \mathbf{d} \mathbf{c}_{-i} / F_{b}^{h}\left(b^{*} \mid \mathbf{s}\right) .
$$

(a) Entry Set:

Start by defining:

$$
F(v, c):=\left(b^{*}-\mathbb{E}\left[\tilde{b}_{h}^{*} \mid \tilde{b}_{h}^{*}<b^{*}, \mathbf{s}\right]\right) F_{\tilde{b}}^{h}\left(b^{*} \mid \mathbf{s}\right)-c,
$$

From the optimal participation strategy we know that $F(v, c)<0 \Rightarrow \delta^{*}=0$ and $F(v, c)>0 \Rightarrow$ $\delta^{*}=1$ (see equation (9)). This function monotonically increases in $v: \frac{\partial F(v, c)}{\partial v}=F_{b}^{h}\left(b^{*} \mid \mathbf{s}\right)>0$. It is further negative for very low $v$ and positive for high $v$ (assuming that both are within the range of $v$ ). Thus there is a single $v^{0}=g_{v}\left(V^{e}, c, \mathbf{s}\right)$ above which entry is profitable and below which it is not. The set $D_{i t}$ is thus defined as $\left[v_{i t}^{0}, \bar{v}\left(\mathbf{x}_{t}\right)\right]$.

What about the derivative of $F$ with respect to $c$ ? From (23) we have:

$$
\frac{d F}{d c}=\frac{\partial b^{*}}{\partial c} F_{\tilde{b}}^{h}\left(b^{*} \mid \mathbf{s}\right)-1
$$

Using the result on the derivative of $b^{*}$ with respect to $c$ proved in the next paragraph, it can be shown that:

$$
\frac{d F}{d c}=\frac{\int_{\mathbf{S}} \int_{g_{v}\left(V^{e}, c, \mathbf{s}^{\prime}\right)}^{\bar{v}\left(\mathbf{x}^{\prime}\right)} F_{\tilde{b}}^{h}\left(b^{*} \mid \mathbf{s}\right) d F_{v}\left(v^{\prime} \mid \mathbf{x}^{\prime}\right) d F_{\mathbf{S}}\left(\mathbf{s}^{\prime}\right)}{\int_{\mathbf{S}} \int_{g_{v}\left(V^{e}, c, \mathbf{s}^{\prime}\right)}^{\bar{v}\left(\mathbf{x}^{\prime}\right)} F_{\tilde{b}}^{h}\left(b^{* \prime} \mid \mathbf{s}^{\prime}\right) d F_{v}\left(v^{\prime} \mid \mathbf{x}^{\prime}\right) d F_{\mathbf{S}}\left(\mathbf{s}^{\prime}\right)}-1
$$


Whether this term is positive or negative depends on the size of today's winning probability compared to tomorrow's expected winning probability.

(b) Derivative of $b^{*}$ with respect to $c$ :

From the optimality condition (12) it follows that:

$$
\int_{\mathbf{S}} \int_{g_{v}\left(V^{e}, c, \mathbf{s}^{\prime}\right)}^{\bar{v}\left(\mathbf{x}^{\prime}\right)}\left(\mathbb{E}_{\tilde{b}_{h}}\left[\mathbf{1}\left\{b_{(1)}<b_{i}\right\}\left(v^{\prime}-V_{i}^{e}-b_{(1)}\right) \mid \mathbf{s}^{\prime}\right]-c\right) d F_{v}\left(v^{\prime} \mid \mathbf{x}^{\prime}\right) d F_{\mathbf{s}}\left(\mathbf{s}^{\prime}\right)=0 .
$$

Using the implicit function theorem, Leibniz's rule and the condition that $F\left(v^{0}, c\right)=0$ we get:

$$
\frac{d V^{e}}{d c}=-\frac{\int_{\mathbf{S}} \int_{g_{v}\left(V^{e}, c, \mathbf{s}^{\prime}\right)}^{\bar{v}\left(\mathbf{x}^{\prime}\right)} d F_{v}\left(v^{\prime} \mid \mathbf{x}^{\prime}\right) d F_{\mathbf{s}}\left(\mathbf{s}^{\prime}\right)}{\int_{\mathbf{S}} \int_{g_{v}\left(V^{e}, c, \mathbf{s}^{\prime}\right)}^{\bar{v}\left(\mathbf{x}^{\prime}\right)} F_{\tilde{b}}^{h}\left(v^{\prime}-V^{e} \mid \mathbf{s}^{\prime}\right) d F_{v}\left(v^{\prime} \mid \mathbf{x}^{\prime}\right) d F_{\mathbf{s}}\left(\mathbf{s}^{\prime}\right)} .
$$

Given that $F_{\tilde{b} \mid \mathbf{s}}^{h}$ is always smaller one the numerator is bigger than the denominator which leads to the derivative being smaller than -1 , hence $\frac{\partial b^{*}}{\partial c}=-\frac{\partial V^{e}}{\partial c}>1$.

Proof of Lemma 3.

(a) Conditional Order Statistics Distribution:

The probability of the event $\left\{X_{m} \geq X_{l}, X_{k} \leq X_{l} \leq x_{(2)}, X_{j} \leq X_{k} \leq x_{(3)} \forall j \neq m, l, k\right\}$ is given by

$$
\begin{aligned}
F^{n-1, n-2: n}\left(x_{(2)}, x_{(3)}, m, l, k\right) & =P\left\{X^{n-1: n} \leq x_{(2)}, X^{n-2: n} \leq x_{(3)}, I^{n: n}=m, I^{n-1: n}=l, I^{n-2: n}=k\right\} \\
& =\int_{-\infty}^{x_{(3)}} \int_{z}^{x_{(2)}}\left(1-F_{m}(u)\right)\left(\prod_{j \neq m, l, k} F_{j}(z)\right) d F_{l}(u) d F_{k}(z) .
\end{aligned}
$$

The probability of the event $\left\{X_{m}, X_{l} \geq X_{k}, X_{j} \leq X_{k} \leq x_{(3)} \forall j \neq m, l, k\right\}$ is given by

$$
\begin{aligned}
F^{n-2: n}\left(x_{(3)},\{m, l\}, k\right) & =P\left\{X^{n-2: n} \leq x_{(3)}, I^{n: n} \in\{m, l\}, I^{n-1: n} \in\{m, l\}, I^{n-2: n}=k\right\} \\
& =\int_{-\infty}^{x_{(3)}}\left(\prod_{j \neq m, l, k} F_{j}(u)\right)\left(1-F_{m}(u)\right)\left(1-F_{l}(u)\right) d F_{k}(u) .
\end{aligned}
$$

Taking derivatives with respect to $x_{(2)}$ and $x_{(3)}$, respectively $x_{(3)}$ gives the corresponding densities. Equation (15) now follows from applying Bayes' theorem.

\section{(b) Identification:}

Since $g^{n-1: n}\left(x_{(2)}, I^{n: n}=m, I^{n-1: n}=l \mid x_{(3)}\right)=\left(1-F_{m}\left(x_{(2)} \mid x_{(3)}\right)\right) f_{l}\left(x_{(2)} \mid x_{(3)}\right)=f^{1: 2}\left(x_{(2)}, I^{2: 2}=\right.$ $\left.m \mid x_{(3)}\right)$ and $\lim _{x_{(3)} \rightarrow-\infty} f^{1: 2}\left(x_{(2)}, I^{2: 2}=m \mid x_{(3)}\right)=f^{1: 2}\left(x_{(2)}, I^{2: 2}=m\right)$ the proof now directly follows from Athey and Haile (forthcoming), Theorem 2. 
Proof of Proposition 2.

(a) Identification of Distribution of Valuations:

Bidder i has $\operatorname{costs} c_{i}$ and continuation value $V_{i}^{e}$ in all periods. At the beginning of each period $\mathbf{s}_{t}$ and $v_{i t}$ realize. Since $V_{i}^{e}$ is considered a constant for the bids of bidder i it follows from the formula for the optimal bids, that, given $\mathbf{s}_{t}$, these vary only with the change in valuations. The econometrician observes these bids only when $\delta_{i t}^{*}=1$. We know from lemma 2 that in that case $v_{i t}>g_{v}\left(c_{i}, \mathbf{s}_{t}\right)$ or equivalently $b_{i t}>g_{v}\left(c_{i}, \mathbf{s}_{t}\right)-V_{i}^{e}$. The observed bids of bidder $i$ thus come form the following parent density:

$$
f_{b_{i}}\left(b \mid \mathbf{s}, \delta_{i}^{*}=1\right)=\frac{f_{v}\left(b+V_{i}^{e} \mid \mathbf{x}\right)}{\int_{z+V_{i}^{e}>g_{v}\left(c_{i}, \mathbf{s}\right)} d F_{v}\left(z+V_{i}^{e} \mid \mathbf{x}\right)} .
$$

Defining $f_{b_{i}}(b \mid \mathbf{x}) \equiv f_{v}\left(b+V_{i}^{e} \mid \mathbf{x}\right)$ we can also write

$$
f_{b_{i}}\left(b \mid \mathbf{s}, \delta_{i}^{*}=1\right)=\frac{f_{b_{i}}(b \mid \mathbf{x})}{\int_{z>g_{v}\left(c_{i}, \mathbf{s}_{t}\right)-V_{i}^{e}} d F_{b_{i}}(z \mid \mathbf{x})} .
$$

Plugging this into equation (15) we obtain

$$
g^{n-1: n}\left(x_{(2)}, m, l \mid x_{(3)}, \mathbf{x}\right)=\frac{\left(1-F_{b_{m}}\left(x_{(2)} \mid \mathbf{x}\right)\right) f_{b_{l}}\left(x_{(2)} \mid \mathbf{x}\right)}{\left(1-F_{b_{m}}\left(x_{(3)} \mid \mathbf{x}\right)\right)\left(1-F_{b_{l}}\left(x_{(3)} \mid \mathbf{x}\right)\right)}
$$

which we know from lemma 3 identifies $F_{b_{j} \mid \mathbf{x}}$ given eBay data. Since $\mathbb{E}\left[b_{i t} \mid \mathbf{x}_{t}\right]=\mathbb{E}\left[v_{i t} \mid \mathbf{x}_{t}\right]-\mathbb{E}\left[V_{i}^{e}\right]$ normalizing $\mathbb{E}\left[v_{i t} \mid \mathbf{x}_{t}\right]=k_{v_{t}}$ and $\mathbb{E}\left[V_{i}^{e}\right]=k_{V e}$ finally identifies $F_{v \mid \mathbf{x}}$.

\section{(b) Identification of Bidding Costs:}

The individual parent bid distributions $F_{b_{j} \mid \mathbf{x}}$ can be used to construct estimates of the unobserved winning bids. The identification of $c_{i}$ then directly follows from equation (14). 


\section{Data}

\section{Data Collection and Cleansing}

The full data set comprise 1232 Compaq Ipaq 3850 auctions from eBay.de. The product was first of all chosen since it is relatively homogeneous and frequently sold at eBay. Secondly,

Table 6: Summary Statistics of Auctions

\begin{tabular}{lcc}
\hline & Full sample & Restricted sample \\
\hline Number of auctions & 1232 & 1029 \\
Number of successful auctions & 1043 & 840 \\
Number of private auctions & 174 & \\
Auctions with last bidding activity earlier & 68 & \\
than 10\% before end of auction & & $469 / 280-872 / 78$ \\
Transaction price (in $€$ ): Mean/Min-Max/Std & $479 / 280-999 / 80$ & \\
Product characteristics: & & $62,98 \%$ \\
- used & $59.08 \%$ & $32.49 \%$ \\
- with extras & $30.28 \%$ & $3.57 \%$ \\
- with foreign operating system & $3.00 \%$ & $2.98 \%$ \\
- with defects & $2.52 \%$ & $33 \%$ \\
Auction details: & & $5.4(7)$ days \\
- Auctions with default minimum bid $(1 €)$ & $33 \%$ & \\
- Average (modus) duration of auction & $5.2(7)$ days & \\
\hline
\end{tabular}

substitution towards competing products was limited since consumer electronics are heavily branded products that cater to different groups. Further, the Ipaq then offered the largest number of new features for the smallest price and was rated best among its competitors by leading German consumer magazines (e.g. Connect). To see whether substitution was really limited, I collected data on a potentially close competitor, the Casio Cassiopeia E-200G. The share of Ipaq bidders that also tried in Casio auctions from April to May was less than 5\%. Substitution, however, did happen towards used Ipaq's and those that came with extras or had smaller defects. The dataset therefore includes all auctions that were open in the category PDAs and Organizers and carried the words "Compaq" and "3850" or "Ipaq" and "3850" in its title. The data contains detailed information on product characteristics which was manually 
retrieved from sellers' descriptions and on auction details. (For details see the table in the next subsection.) Further all bids and some bidder characteristics are available.

Since all estimation procedures rely on the availability of a panel, all auctions with the feature 'private', where no information on bidders' identities is available, have to be dropped. Further, since it is assumed that it is not optimal for a bidder to reveal any information about her true willingness to pay before the last minutes of an auction (Vickery assumption), I consider early bids as not informative and delete them from the panel. A small number of auctions is also affected by this rule. Table 6 provides summary statistics for the full and restricted auction sample. It is shown that auction characteristics are little effected by concentrating on non-private auctions with bidding activity towards the end.

By restricting the bids to those that are submitted in the last $10 \%$ of the time, the number of bids reduces from 7630 to 3202 observations. (If a bidder bids several times in the same auction only the last bid is counted.) The $10 \%$ mark is found by striking a balance between the informativeness of the bids and the number of remaining observations per bidder. Figure
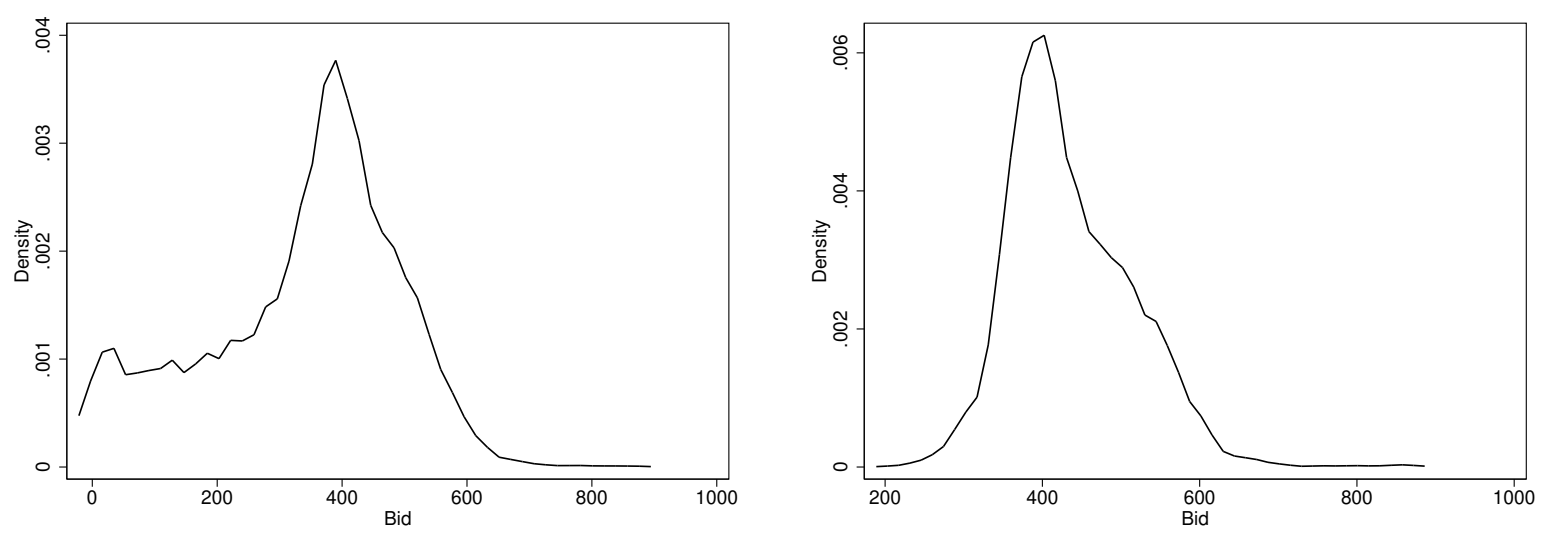

Figure 4: Density of All Bids and Bids Submitted in Last $10 \%$ of an Auction.

4 displays the bid distribution in the full (left) and the restricted sample (right). The full distribution displays a second peak at very low prices. This is due to a number of bids between $1 €$ and $20 €$. Bidders will hardly believe, they will win with these bids. One explanation why bidders engage in these bids is that it is an easy way to track an auction. ${ }^{27}$ By excluding early bids the two peakedness of the distribution disappears. Table 7 compares summary statistics

\footnotetext{
${ }^{27}$ As opposed to eBay.com at eBay.de auctions that are closed cannot be searched for anymore. Alternative
} 
for the full and the restricted bid samples.

Table 7: Summary Statistics of Bidders

\begin{tabular}{lcc}
\hline & Full sample & Restricted sample \\
\hline Number of bids & 7630 & 3182 \\
Number of individual bidders & 3829 & 1968 \\
Av. number of trials & 2 & 1.6 \\
Importance of "switching back"* & $9.72 \%$ & $3.1 \%$ \\
Importance of "simultaneous bidding"** & $10.13 \%$ & $3.6 \%$ \\
Bidder is observed in sample for: & & \\
$\quad$ Mean & 5.65 days & 7.15 days \\
$\quad$ Quantiles $(25$ 50 75) & & 0 min 2.44 hin 3.98 days \\
Bids (in $€$ ): & $334 / 1-827 / 155$ & $439 / 203-872 / 79$ \\
$\quad$ Mean/Min-Max/Std. dev & 52.21 & 27.13 \\
Av. std. dev. per bidder & & \\
\hline
\end{tabular}

* Percentage of bids, placed by a bidder in an auction $t$ after she was outbid in auction $t+1$.

* Percentage of bids, placed by a bidder while she still had a standing bid in another auction.

ways for obtaining information on the price at which an auction closed are to use eBays tracking service ("observe auctions"), to remember the ID of an auction and construct the URL afterwards manually, or to just participate, since participants receive an email with all the necessary information at the end of the auction. 


\section{Description of Variables Used in Regression}

\begin{tabular}{|c|c|c|}
\hline Category & Variable & Description \\
\hline \multirow{3}{*}{ Product Quality } & AGE/AGE NA & $\begin{array}{l}\text { Age in days as stated by the seller/1 if age } \\
\text { is not mentioned in description }\end{array}$ \\
\hline & OS FOREIGN & 1 if English or French operating system \\
\hline & DEFECTS & $\begin{array}{l}1 \text { if product comes without bill, lacks stan- } \\
\text { dard accessory, has scratches on the display } \\
\text { or other defects }\end{array}$ \\
\hline \multirow{6}{*}{ Extras } & JACKET1-5 & $\begin{array}{l}1 \text { if with PC Card Jacket (1), CF Card } \\
\text { Jacket (2), Dual Slot Jacket (3), Bluetooth } \\
\text { Jacket (4), GSM/GPRS Jacket (5) }\end{array}$ \\
\hline & HARDDISK & $\begin{array}{l}1 \text { if with external memory in form of } \\
\text { Toshiba } 1 \text { GB harddisk }\end{array}$ \\
\hline & NAVIGATION & $\begin{array}{l}0,1 \text {, or } 2 \text { depending on the scope of the } \\
\text { included navigation system }\end{array}$ \\
\hline & MEMORY & $\begin{array}{l}\text { Amount in MB of external memory in form } \\
\text { of } \mathrm{CF}, \mathrm{SD} \text {, or MMC } \operatorname{card}(\mathrm{s})\end{array}$ \\
\hline & CAREPAQ & $\begin{array}{l}0,1,2 \text {, or } 3 \text { depending on the scope of the } \\
\text { additional producer warranty }\end{array}$ \\
\hline & \multicolumn{2}{|c|}{ For the estimation these details are grouped as described in the text. } \\
\hline \multirow{4}{*}{ Auction details } & TREND & Ending date of auction or bidding time \\
\hline & MINIMUM BID & $\begin{array}{l}\text { Minimum bid required by the seller to en- } \\
\text { ter an auction }\end{array}$ \\
\hline & DURATION & $\begin{array}{l}\text { Categorial Variable, either } 3,5,7 \text {, or } 10 \text {, } \\
\text { depending on the length of the auction }\end{array}$ \\
\hline & \multicolumn{2}{|c|}{$\begin{array}{l}\text { Other details: A seller can further chose the option privat (bidder } \\
\text { pseudonyms are not revealed) and buy-it-now (fixed price option, see } \\
\text { description in text) }\end{array}$} \\
\hline
\end{tabular}




\section{Frequency of Trials}

\begin{tabular}{rrrrrrr}
\hline & \multicolumn{3}{c}{ Full Sample } & \multicolumn{3}{c}{ Restricted Sample } \\
\# of trial & Freq. & Percent & Cum. & Freq. & Percent & Cum. \\
\hline 1 & 2,505 & 65.44 & 65.44 & 1389 & 70.58 & 70.58 \\
2 & 603 & 15.75 & 81.19 & 296 & 15.04 & 85.62 \\
3 & 285 & 7.45 & 88.64 & 149 & 7.57 & 93.19 \\
4 & 152 & 3.97 & 92.61 & 60 & 3.05 & 96.24 \\
5 & 92 & 2.4 & 95.01 & 31 & 1.58 & 97.82 \\
6 & 49 & 1.28 & 96.29 & 12 & 0.61 & 98.43 \\
7 & 36 & 0.94 & 97.23 & 8 & 0.41 & 98.83 \\
8 & 19 & 0.5 & 97.73 & 8 & 0.41 & 99.24 \\
9 & 15 & 0.39 & 98.12 & 3 & 0.15 & 99.39 \\
10 & 12 & 0.31 & 98.43 & 5 & 0.25 & 99.64 \\
11 & 9 & 0.24 & 98.67 & 2 & 0.10 & 99.75 \\
12 & 6 & 0.16 & 98.82 & 1 & 0.05 & 99.80 \\
13 & 7 & 0.18 & 99.01 & 2 & 0.10 & 99.90 \\
14 & 3 & 0.08 & 99.32 & 0 & 0.00 & 99.90 \\
$>14$ & 36 & 0.98 & 100.00 & 2 & 0.10 & 100.00 \\
\hline Total & 3,829 & 100.00 & & 1,968 & 100.00 & \\
\hline
\end{tabular}




\section{Participation Decision}

Before estimating a binary choice model, the participation decisions of bidders have to be elicited from the data. A bidder obviously participates, that is, $\delta^{*}=1$, if she places a bid. Since it is not known whether the auctions in which a bidder did not bid were part of her choice set at all, the decision not to participate is not directly observable in the data. The following figure shows a bidders observed participation. 1 signifies that a bidder placed a bid, while - and $\mathrm{O}$ denote that no bid was observed. The structural model though claims, a bidder is active as long as

\begin{tabular}{cc|ccc|c} 
bidder/auction & 1 & 2 & 3 & 4 & 5 \\
1 & 1 & $\mathrm{O}$ & $\mathrm{O}$ & 1 & - \\
2 & - & 1 & $\mathrm{O}$ & 1 & - \\
3 & - & - & - & 1 & - \\
4 & - & - & - & - & 1
\end{tabular}

she has not won a product. The first assumption, which follows from the theoretic model, thus is that a bidder considered all intermediate auctions, that is, $\mathrm{O}$ is equivalent to $\delta^{*}=0$. It can further be assumed that those auctions with ending dates in between the time the first bid is placed and the end of this first auction of bidder i were observed by the bidder but not chosen, so that also here $\delta^{*}=0$. All these decisions are now collected in the vector $\delta_{I P}$.

The assumption, a bidder entered the eBay marketplace when first observed in the data is not realistic since it states that the first participation decision is always affirmative. Further the bidder might also consider a few more auctions after being observed last before finally exiting. Both assumptions understate the share of $\delta^{*}=0$. In a second approach, I therefore try to correct for this bias by making somehow more sophisticated assumptions. First, bidders are divided into groups according to the number of bids with which they are observed. Then, the average number of Os between two bids are computed for each group. Half of this number will be added in form of $\delta^{*}=0$ at the beginning of the observational period for each bidder in the same group. In case the bidder leaves the auction without winning, another half is added at the end. The rational behind this approach is that bidders with the same entry costs have ex ante, that is before the auction specifics realize, in expectation the same number of trials. ${ }^{28}$ The observed number of

\footnotetext{
${ }^{28}$ If the errors have a logistic distribution it further was shown by Andersen (1970) that the number of trials are a sufficient statistic for the unknown individual effects.
} 
times it takes a bidder to participate in a new auction (Os) is on the other hand a proxy for the time it took a bidder with similar bidding costs to enter the first auction. These decisions are now collected in $\delta_{I_{S}}$. The following table provides summary statistics for the two entry panels:

\begin{tabular}{lcccc}
\hline & \multicolumn{2}{c}{$\delta_{I P}$} & \multicolumn{2}{c}{$\delta_{I S}$} \\
\hline Total number of observation & full & window & full & window \\
Percentage of $\delta=1$ & 15580 & 8997 & 19666 & 11083 \\
\hline
\end{tabular}

The fact that the panel arbitrarily begins at auction 1 and ends at some auction $\mathrm{T}$ leads to an under-representation of $\delta^{*}=0$. To circumvent this problem in the later estimation, I will only use a shorter window from the middle which in the figure is equivalent to auctions 2 to 4 . This does not create any bias as long as the auction details do not change in a systematic way over time. In the above example this restriction causes that bidder 4 will not be relevant for the estimation; bidder 3 is denoted as a one time participant, while 2 and 3 both evaluated all three auctions 2-4.

While I consider the non-successful auctions in the construction of both panels, the private auctions are dropped since no information on bidders' pseudonyms are available. Also those bids that were placed before the last $10 \%$ of the auction are left aside. That is, if a bidder only places a bid early on in the auction I denote that she did not participate in the auction.

The selection equation is estimated for both $\delta_{I_{p}}$ and $\delta_{I_{s}}$. The differences between the two endogenous variable vectors are small as well as for different subgroups of bidders. Table 4 reports results for the given window of $\delta_{I_{s}}$. 